\title{
Augusto y la geometría. Sobre las bases geográficas de la dominación romana
}

\author{
Sabine PANZRAM \\ Universidad de Hamburgo \\ Sabine.Panzram@uni-hamburg.de
}

\begin{abstract}
RESUMEN
Este artículo trata la cuestión del conocimiento que tenían los miembros de la élite romana de época augustea sobre el territorio que dominaban. Para ello, la Península Ibérica sirve como "caso de prueba" y el "objeto" son las ciudades en las que estaba basada la dominación romana. La presentación de los conocimientos geográficos sobre ese espacio que han llegado a nosotros gracias a Eratóstenes, Polibio, Estrabón, Plinio y otros autores, por un lado deja patente qué "mundo" tenían en mente los imperatores, los gobernadores y los miembros de las comisiones senatoriales cuando tomaron las decisiones concernientes a la fundación de ciudades. Por otro lado, nos muestra que las "imágenes del mundo" o los mapas basados en estos conocimientos teóricos reflejan un enfoque científico que se oponía diametralmente a la orientación práctica cotidiana. Dicho enfoque bebía directamente de las experiencias transmitidas oralmente, que el primer princeps supo aprovechar como nadie; en efecto, la demarcación fronteriza que llevó a cabo con ayuda de la geometría se basó en estructuras maduradas, y por tanto sirvió para integrar, pero no para homogeneizar, la multitud de etnias preexistente.
\end{abstract}

Palabras clave: Augusto. Res gestae. Geografía. Península Ibérica. Valle del Ebro. Fundación de ciudades.

\section{Augustus and Geometry. The Geographic Basis of Roman Dominion}

\begin{abstract}
The paper presented here raises the question of what members of the Roman elites in the time of Augustus knew about the space they ruled. As "case study" serves the Iberian Peninsula and as "object" the cities considered to be the fundaments of Rome's dominion. The outlining of the geographical knowledge that we find in Eratosthenes, Polybios, Strabo, Pliny and others shows on one hand what understanding of the world imperatores, governors and member of the decemviri had in mind when they decided about founding cities. On the other hand, it demonstrates that images of the world based on this knowledge or cartography reflect a scientific perspective that is opposite to daily, practical orientation within the space. Concerning the latter, knowledge based on experience traded down orally was the most important, and the first princeps obviously had a commanding knowledge of it. The limits he put handling geometry were based on traditional structures, thus made possible the integration of a diversity of ethnic groups but not their homogenization.
\end{abstract}

Key Words: Augustus. Res gestae. Geography. Iberian Peninsula. Valley of the Ebro. Foundation of cities. 
Augusto era conocido por su personalidad precavida. No solo depositó su testamento, sino también tres rollos de documentos para que fuesen custodiados por las Vestales y fuesen abiertos y leídos en el Senado en caso de fallecimiento: Junto a los mandata para sus funerales y un breviarium totius imperii, un resumen del conjunto de la administración imperial con listados de tropas, del patrimonio del Estado y de los impuestos pendientes de recaudación, los documentos contenían un index rerum gestarum, un catálogo de sus hazañas. ${ }^{1}$ Este relato debía ser grabado en bronce y colocado delante de su mausoleo en el campo de Marte, una parte de Roma que Augusto convirtió en un "paisaje artístico", comenzando nada más que llegar al poder, en cuestión de dos décadas. ${ }^{2}$ Por medio de sus parques, áreas acuáticas y deportivas, la zona había adoptado un carácter tan idílico como placentero, tenía un aire sacro debido a los mausoleos y los centros de culto dinástico, y casi cósmico con el solarium Augusti y el ara Pacis. Dichas características peculiares se manifestaban todos los años el día del aniversario de Augusto: cada 23 de septiembre, la sombra arrojada por este reloj solar de dimensiones desconocidas hasta la fecha, que tenía como gnomon un obelisco egipcio, ${ }^{3}$ se proyectaba sobre el centro del altar dedicado por el Senado al princeps a su regreso de las Galias e Hispania, ${ }^{4}$ mostrando que la constelación astrológica del momento de su nacimiento ya estaba vinculada con la pax augusta.

Por tanto, en esa parte de la urbs que a ojos de un contemporáneo de origen griego como Estrabón representaba la mismísima esencia de Roma, delante del Mausoleo (un túmulo sempervirente que descansaba sobre mármol blanco y coronado por una estatua broncínea colosal del emperador), en unas tablas fijadas sobre pilares de mármol, podían leerse las gestas con las que Augusto había sometido el orbe terrestre a la dominación del pueblo romano. ${ }^{5}$ Las Res Gestae (25-33) como tal figuran después de los honores que obtuvo (1-14) y las impensae et largitiones, sus desembolsos financieros (15-24); el texto finaliza con la alusión, por un lado, a la sesión del Senado del 13 de enero del año 27 a.C., desde la cual Augusto superaba a todos sus colegas en auctoritas, pero no en potestas (34-35), y, por otro lado, mencionando la concesión del título de pater patriae. De entre sus proezas, Augusto destaca la pacificación de provincias importantes desde el punto de vista estratégico como las Galias, Hispania y Germania, además de los pueblos alpinos (26), y también resalta las exploraciones navales (como las del Océano) y terrestres (como las de Etiopía y Arabia). Enumera las regiones que logró anexionar a los dominios romanos, como Egipto y Armenia (27), al igual que las zonas otrora sometidas al poder de Marco Antonio y Sexto Pom-

1 Suet., Aug. 101.1 y 4; Cass. Dio, 56.33.1-3.

2 Estas medidas urbanísticas y arquitectónicas convirtieron al campo de Marte en una "gran obra", probablemente en la mayor obra contemporánea del Imperio: se sucedían la colocación de cimientos, los trabajos de rehabilitación, las inauguraciones y los festejos de apertura; véase a ese respecto HöLSCHER 2000, 237-281; REHAK 2006; HASELBERGER 2007, 71-193, en concreto 127.

3 Plin., nat. 36.69-71; la inscripción en su zócalo (CIL VI, 702) recordaba a la victoria "sobre Egipto", desde la que ya habían transcurrido 20 años.

4 R. Gest. div. Aug. 12; Ov., fast. 1.709-722; Plin., nat. 36.72.

5 Str., 5.3.8. - R. Gest. div. Aug.: Rerum gestarum divi Augusti, quibus orbem terra[rum] imperio populi Rom[a]ni subiecit, et impensarum, quas in rem publicam populumque Romanum fecit, incisarum in duabus aheneis pilis, quae su[n]t Romae positae, exemplar sub[i]ectum. 
peyo y que él logró reconquistar. También relata la recuperación de los estandartes de los partos por vía diplomática (29), las guerras de Panonia y Dacia (30) y las visitas de legados escitas, Albani e incluso de los reyes indios, que "nunca antes" habían sido vistos en Roma (31). Además menciona la creación de colonias de veteranos en África, Hispania y otras provincias, y la fundación de coloniae dentro de la misma Italia (28).

Tanto la inclusión de estos méritos en las Res Gestae como su propia ordenación sugieren que estas deben entenderse como la base de su autoridad; sus avances hasta las fronteras del mundo condicionaron el nuevo orden establecido y garantizado por él. Pueden contarse un total de 55 denominaciones geográficas que, según afirma Claude Nicolet, fueron mencionadas y posicionadas con toda la intención. ${ }^{6}$ Por un lado, Augusto nombra 13 provincias (Achaia, Aegyptus, Africa, Asia, Cyrenae, Galliae, Hispaniae, Illyricum, Macedonia, Narbonensis, Pisidia, Sicilia y Syria) junto con 24 pueblos y países (Adiabeni, Aethiopia, Albani, Arabia Eudaimon, Armenia, Bastarnae, Britanni, Charydes [o Herudes], Cimbri, Daci, Dalmati, Germani, Hiberi, India, Marcomani, Medi, Pannoni, Parthi, Sabaei, Sarmatae, Scythae, Semnones, Suevi y Sugambri), a los que Roma había vencido en la contienda, anexionado y sometido o que habían suplicado a Roma que designase nuevos reyes. Por otro lado, sólo cita cuatro ríos explícitamente (Albis, Danuvius, Rhenus y Tanaïs), unas montañas (Alpes), cuatro mares (Oceanus, Hadrianum mare, Tuscum mare, Oriens) y seis oppida: Actium, Ariminum, Gades, Mariba, Meroe y Nabata. Algunos de estos nombres y denominaciones se pueden leer aquí por primera vez, mientras que otros eran ya conocidos por fuentes literarias; tal es el caso de los Adiabeni y su rey Artaxares y de Arabia, quae appellatur Eudaemon, mientras que los Daci ya habían aparecido en el Bellum Gallicum de César. ${ }^{7}$ Es evidente cuál fue la intención de Augusto: quiso mostrar que jamás nadie se había atrevido a llegar tan lejos, y que él había avanzado hasta las fronteras del orbis terrarum. Así, su flota "surcó el Océano desde la desembocadura del Rin hacia regiones orientales y los territorios de los cimbrios, adonde

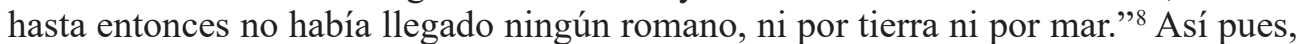
superó a Julio César, que se había detenido a orillas del Rin. Pero no solo se ganó este mérito en el norte; sus expediciones meridionales llegaron a la ciudad etíope de los nabateos, próxima a Meroe y en Arabia, hasta la ciudad de Mariba. ${ }^{9}$ Hacia el oeste su poder se expandía hasta el cabo de San Vicente, más allá de las columnas de Hércules; al este terminaba en la India, emulando a Alejandro Magno: al igual que este hiciera con Oriente, Augusto sometió a Occidente. ${ }^{10} \mathrm{Y}$ al referirse al río Tanaïs (Don), hace alusión a la frontera tradicional entre Europa y Asia. ${ }^{11}$ Con tales acciones, Au-

6 Nicolet 1988, esp. 27-40.

7 R. Gest. div. Aug. 32 resp. 26; Caes., bell. Gall. 6.25.2.

8 R. Gest. div. Aug. 26: (...) Cla[ssis m] ea p[er Oceanum] ab ostio Rheni ad solis orientis re / gionem usque ad fi[nes Cimbroru] m navigavit, quo neque terra neque mari quisquam Romanus ante id tempus adit; (...).

9 R. Gest. div. Aug. 26: (...) in Aethiopiam usque ad oppidum Nabata pervent[um] est, cui proxima est Meroe. In Arabiam usque ad fines Sabaeorum pro[cess] it exercitus ad oppidum Mariba.

10 Sobre las características de esta imitatio NiCOLET 1988, 97-98; ROMM 1992, 20-26 y 140-171; KüHNEN 2008, 107-140.

11 Mela, 1.8. 
gusto pretendía aumentar la fama militar que se había ganado directamente mediante las expediciones geográficas indirectas ${ }^{12}$ a la par que demostrar de forma metódica, a través de listados, que poseía unos conocimientos geográficos tan precisos como pioneros.

¿Pero qué se sabía en Roma sobre esta área geográfica cuya dominación se arrogaba el princeps? Las representaciones del espacio controlado existentes en las inmediaciones del lugar en el que se ubicaban las Res Gestae sugerían unos conocimientos profundos, puesto que podía admirarse el aspecto de este orbis terrarum apenas a unos cientos de metros del mausoleo: en la porticus Vipsania, cuyas paredes estaban cubiertas por un mapamundi. ${ }^{13} \mathrm{Y}$ también a pocos cientos de metros se encontraba el foro de Augusto, en el que, según Veleyo Patérculo, "resplandecían" los tituli de las gentes, una serie de estatuas o representaciones alegóricas de las provincias y las etnias sometidas. ${ }^{14}$ ¿Qué sabían el princeps y los miembros de la élite sobre los territorios allí presentes, unos territorios conquistados, dominados y administrados por ellos? ¿Qué mostraba el mapa del mundo que Agripa probablemente había encargado por orden de Augusto? ¿Litorales, ríos, montañas, ciudades, fronteras, pueblos reales o seres de fábula? ¿Qué apariencia tenía este mundo? ¿Y con qué propósito se había trazado esta imagen de la tierra?

A continuación quisiera intentar mostrar qué conocimientos geográficos tenían los miembros de la élite romana sobre el terreno que dominaban. Para ello me serviré de la Península Ibérica como "caso de prueba", es decir, la región mediterránea en la que Roma se vio obligada por primera vez a perpetuar su poder a una distancia considerable de la Península Itálica, en un territorio prácticamente desconocido y con una población "bárbara"; mi "objeto" serán las ciudades en cuya autonomía y autarquía se basaba en última instancia su dominación. El punto de partida de mi desarrollo es la presentación esquemática del saber geográfico sobre este territorio, tal y como se desprende de los autores de época republicana, entre ellos Eratóstenes y Polibio, y de comienzos del Principado, es decir, Estrabón y Plinio. ${ }^{15}$ Comenzamos por ese punto porque imperatores, gobernadores y miembros de comisiones senatoriales tomaban sus decisiones con ese "mundo en mente", por ejemplo sobre la fundación y destrucción de ciudades, y en esas decisiones se basaban a su vez las medidas adoptadas por el primer princeps, que podían ser la concesión de privilegios como el nombramiento

12 En época del primer princeps, no solo tuvieron lugar las expediciones militares de Elio Galo en el año 25-24 a.C. hacia Arabia felix y las de C. / P. [?] Petronio entre los años 24-22 a.C. a Meroe (Sudán), sino también la de Cornelio Balbo a los garamantes (Libia) en el año 20 a.C., por ejemplo. Véase al respecto NICOLET 1988, 98-101; cf. HeNnig 1944², 301-313.

13 Plin., nat. 3.16-17; Cass. Dio, 54.29.4; 55.8.9.

14 Vell., 2.38.1 y 39.2: Divus Augustus praeter Hispanias aliasque gentes, quarum titulis forum eius praenitet, paene idem facta Aegypto stipendiaria, quantum pater eius Galliis, in aerarium reditus contulit. Los monumentos que portaban los tituli, como por ejemplo una estatua de oro macizo que pesaba 100 libras, dedicada a Augusto por la Bética (CIL VI, 8,2 31267), parece que se encontraban a la derecha del templo de Mars Ultor y a unos $50 \mathrm{~m}$ de distancia del centro de la plaza; véase al respecto ALFöLDY 1989, 226-235.

15 Fundamental sobre esta temática veáse CRUZ ANDreOTTI ET ALII 2006; también CRUZ ANDREOTTI ET ALII 2007; Gómez Fraile - Albaladejo Vivero 2012, 359-424. A continuación solo se citará la bibliografía imprescindible para proseguir el análisis y mi argumentación; es decir, que no se tendrá en cuenta, por ejemplo, el estatus jurídico de las poblaciones fundadas; a ese respecto, véase EsPINOSA EsPINOSA 2014. 
de la capital de un conventus. La cuestión de si se utilizaban mapas para la toma de decisiones o durante las campañas militares (lo que nos llevaría al apasionado debate que mantienen los estudiosos sobre hasta qué punto se puede suponer la existencia de material cartográfico en la Antigüedad), ${ }^{16}$ resulta secundaria, puesto que nos encontramos ante dos discursos diferentes entre los que, como se mostrará más adelante, había una distancia abismal: uno procedente de la ciencia y otro basado en la experiencia práctica.

\section{La teoría geográfica sobre el espacio}

Los romanos no fueron el primer pueblo foráneo en llegar a la Península Ibérica. Los fenicios ya conocían sus costas desde el siglo VIII y los griegos, desde el siglo VI a.C.; estos fundaron factorías en la costa sur respectivamente establecieron delegaciones comerciales en el transcurso de la gran colonización del Mediterráneo. ${ }^{17}$ Los primeros testimonios sobre la forma de la Península Ibérica y sobre su población se los debemos a los viajes de descubrimiento y exploración, sobre todo los emprendidos por Piteas de Marsella (c. 380-310 a.C.). ${ }^{18}$ Piteas navegó en torno al año 330 a lo largo de la costa norte y occidental de la Península Ibérica y del litoral norte de la Galia, hasta que dio con las Islas Británicas y finalmente llegó a Tule. Eratóstenes de Cirene (c. 275-194 a.C.) pudo basarse en sus conocimientos para trazar una imagen del mundo que iba a influir en las representaciones cartográficas de los tres siglos posteriores: Su oikumene tenía casi forma de elipse, con el doble de largo que de ancho aproximadamente, y se extendía de Tule a Meroe y del cabo de San Vicente hasta el Ganges. ${ }^{19}$ Daba la impresión de que en este mapa se habían forzado demasiado las representaciones de los accidentes geográficos naturales (Fig. 1); las había clasificado en esfrágides (sphragides), figuras geométricas simples, ya que los intelectuales griegos habían desarrollado un conocimiento espacial y del mundo que en esencia dimanaba de las matemáticas, la construcción y el pensamiento, y que interpretaba la experiencia empírica desde esa óptica. ${ }^{20}$ Por otra parte, Eratóstenes marcó las pautas de las representaciones de la Península Ibérica que circularon durante el siglo II a.C., a pesar de no haberla visto nunca, como constató Estrabón disculpándole por

16 Pese a que no ha llegado hasta nosotros ni un solo mapa, la communis opinio (de la cual son buena muestra DiLKe 1985 y HARLEY - WOODWARD 1987) asumió la existencia de conocimientos y materiales cartográficos, aludiendo, entre otros, al mapamundi de Agripa, los escritos de los agrimensores, la forma urbis, el catastro de Orange y la tabula peutingeriana, así como la transmisión literaria. Por el contrario, BRODERSEN 1995 rechazó esta opinión principalmente por la falta de un concepto de escala, y antes que él, JANNI 1984 había advertido en tono provocador sobre la necesidad de revisar la cuestión. Acerca del status quo del debate, véase RATHMANN 2013, 11-49.

17 Aubet 20012; López de la Orden 2011; Cabrera Bonet - SÁnchez Fernández 2000.

18 MetTe 1952, frg. 7a y 8; al respecto Dion 1977, 175-222; en general, CAMACHO Rojo-Fuentes GonZÁLEZ 2012, 1774-1780.

19 BERGER 1964, 363-368, cf. ahora la traducción y el comentario de RoLLER 2010; en cuanto a la biografía y la influencia de Eratóstenes Aujac 2001; Geus 2002.

20 Acierta GeHRKe 1998, 163-192, en concreto 182: "Die Erde wurde hier auf das Prokrustesbett der Geometrie gelegt". 
su desconocimiento. ${ }^{21} \mathrm{El}$ de Cirene se vio obligado a recurrir a literatura en la que confiaba, como la de Piteas, a pesar de que éste había recorrido esas distancias como un "particular desprovisto de medios" 22 y había achacado sus exiguas nociones sobre el lugar a la hostilidad cartaginesa, que impedía adquirir conocimientos sólidos sobre los territorios occidentales. ${ }^{23}$ Dado que las Geographika fueron redactadas probablemente en las dos últimas décadas del siglo III, los sucesos de la Segunda Guerra Púnica podrían haber llevado a que Carthago tuviese unas nociones aproximadas de este territorio. Al menos, de la costa mediterránea y de partes de la costa atlántica hasta la altura de Gades (Cádiz), así como del interior hasta la cuenca del Durius (Duero), pero quizás no permitiese acceder a esos conocimientos. ${ }^{24}$ En cualquier caso fue Eratóstenes quien reconoció la forma de Iberia como península e identificó los Pirineos como la cadena montañosa que unía la península con el continente, habló de distancias, las localizó en la oikumene y las dibujó. ${ }^{25}$

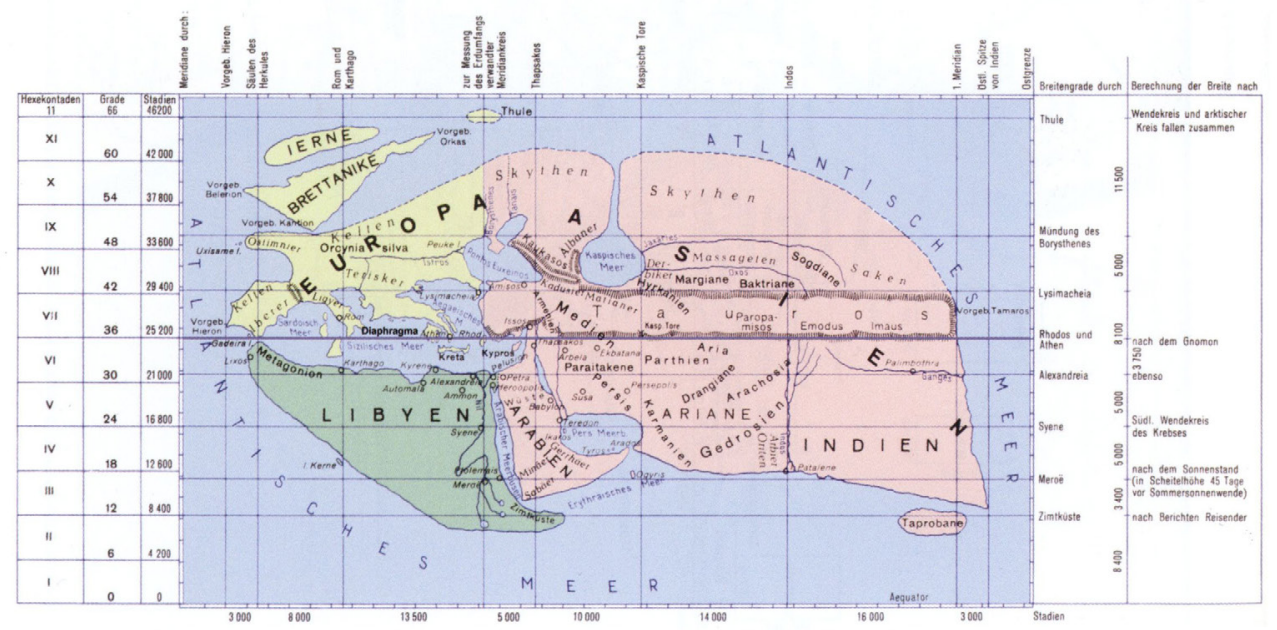

Fig. 1. Representación de la oikumene de Eratóstenes.

ENGELS 2007, 130 fig. 2.

Posiblemente también se redujese a esta imagen de Eratóstenes la idea que tenían Publio y Cneo Escipión en el año 218, cuando tomaron tierra en Emporiae (Ampurias) para defender sus dominios ante el peligro que suponía la rápida expansión de la epicracia cartaginesa. ${ }^{26} \mathrm{La}$ ampliación de los conocimientos sobre este territorio se debió sobre todo a las marchas de las legiones; si hubo o no expediciones con esta

21 Str., 2.4.2.

22 Str., 2.4.1-2 se refiere a esta duda de Polibio Plb., 34.5 (cf. también 3.2.11).

23 Berger 1964, frg. 1 B, 9.

24 Plb., 3.14; Liv., 21.5.

25 Sobre las observaciones astronómicas y los cálculos matemáticos de Eratóstentes, véase el estudio detallado de Gómez Fraile - Albaladejo Vivero 2012, 362-375.

26 Al respecto por ejemplo RichARDSON 2004, cf. CURCHIN 1991; KocH 1993, 1-40. 
finalidad es algo que escapa a nuestro conocimiento. Sin embargo, es de suponer que el ejército contase con un agrimensor y un cartógrafo, y que sus mapas se guardasen en el archivo estatal o tabularium, donde podían ser consultados en caso de interés, junto con el informe de actividades que todo general debía presentar ante el Senado al regreso de su provincia, primero de viva voz y después por escrito. ${ }^{27}$ Del resumen de un informe de ese tipo transmitido por Livio, ${ }^{28}$ el que realizó Publio Cornelio Escipión del año 206 a.C., no cabe concluir si contenía además información de tipo geográfico y etnográfico. No obstante, los datos que el cónsul Marco Porcio Catón, vencedor en Ampurias en el año 195, intercala en su presentación de la historia de Roma, Origines, sirven como muestra para atestiguar que Roma tenía un interés general y cierto conocimiento sobre el tema: Habla de "fabulosas minas de hierro y plata" y de una "montaña de sal maciza", añadiendo que "cuanto más material se extrae de allí, más se forma". ${ }^{29}$ También conocía el viento del norte tan característico del valle del Ebro, el cercius, capaz de derribar a un soldado armado o un carro repleto de carga, y sabía de la riqueza pesquera del río "grande y bello" que nacía en el territorio de los cántabros. ${ }^{30}$ Catón entremezcla así posibles experiencias propias y hechos conocidos, como los recursos minerales de esta región y las salinas, con los relatos que circulaban, pues probablemente todavía no hubiese llegado ningún representante de Roma hasta el manantial del Ebro.

En cualquier caso, a lo largo del siglo II la Península Ibérica poco a poco dejó de ser ese espacio difuso entre la realidad y el mito, a cuyas ciudades costeras se dirigían algunos comerciantes esporádicamente y conocido porque el mundo terminaba en las columnas de Hércules. A ello contribuyó el constante avance de la conquista territorial (Roma ya no solo estaba presente en el litoral, sino también en el valle central del Ebro, en el nacimiento del Guadalquivir, al este de la Submeseta Sur y en la mayor parte de la Turdetania), además de un bellum prope novum o un lusitano y una ciudad celtíbera: Viriato y Numancia. Las derrotas ante Viriato y el asedio de Numancia que tuvieron lugar entre los años 154 y 133, en cierto modo conmocionaron la autoconsciencia romana de tal forma que, desde una óptica retrospectiva, parecía que verdaderamente se estuviese cuestionando cuál de los dos pueblos debía obedecer al otro. ${ }^{31}$ En consonancia con lo anterior, la Iberia de Polibio (209/208-127 a.C.), a la

27 Véase al respecto Pina Polo 2011, 39-53, aquí 41; por el contrario CADIOU 2006, 135-152, esp. 141-142, se muestra más crítico sobre la información disponible.

28 Liv., 28.38.2: Haec in Hispania P. Scipionis ductu auspicioque gesta. Ipse L. Lentulo et L. Manlio Acidino provincia tradita decem navibus Romam rediit et senatu extra urbem dato in aede Bellona, quas res in Hispania gessisset, disseruit, quotiens signis conlatis dimicasset, quot oppida ex hostibus vi cepisset, quas gentes in dicionem populi Romani redegisset; adversus quattuor se imperatores, quattuor victores exercitus in Hispaniam isse; neminem Carthaginiensem in iirs terris reliquisse; cf. también 41.6.4.

29 Liv., 34,14-15; App., Ib. 14. BECK - WALTER 2001, 148-224, aquí frg. 5,2: Sed in his regionibus ferrareae, argentifodinae pulcherrimae, mons ex sale mero magnus, quantum demas, tantum adcrescit. ventus Cercius, cum loquare, buccam implet, armatum hominem, plaustrum oneratum percellit.

30 BeCK - WALter 2001, 148-224, aquí frg. 7,5: fluvium Hiberum; is oritur ex Cantabris, magnus atque pulcher, pisculentus.

31 Liv., 33.26.1-7; Vell., 2.90.3: (...) illa <terra > tot consulares, tot praetorios absumpsit duces, patrumque aetate in tantum Sertorium armis extulit, ut per quinquennium diiudicari non potuerit, Hispanis Romanisne in armis plus esset roboris et uter populus alteri pariturus foret. 
que este conocía de primera mano, ${ }^{32}$ era la de los enfrentamientos militares: gracias a su "geografía de los militares" no solo tenemos nociones de los alrededores de Carthago Nova (Cartagena) y de su topografía, sino también de la información pormenorizada que un estratega como Publio Cornelio Escipión ordenó recabar y supo utilizar con éxito durante el ataque a una ciudad hostil. ${ }^{33}$ Polibio es consciente de que esta es la Iberia "real", que se oponía diametralmente al espacio tematizado por otros historiadores. ${ }^{34}$ En general emplea la forma de la península con los Pirineos como frontera y da por hecho que estos, al igual que las columnas de Hércules, se adentran como promontorios hacia el mar; nombra, por un lado, ciudades costeras destacadas desde el punto de vista político y de importancia estratégica como Carthago Nova y Saguntum y, por otro lado, cita ríos como el Ebro o cordilleras como Idubeda, el sistema Central. ${ }^{35}$ Sin embargo fue también el responsable de una confusión que afecta la orientación de los Pirineos, que tendrá importantes consecuencias. Eratóstenes había localizado la cadena montañosa correctamente de este a oeste, pero Polibio lo censuró y postuló una orientación de norte a sur, de forma que Galia no quedaba al norte, sino al este de la Península Ibérica. Este error fue mantenido y reproducido grosso modo por Estrabón, Mela, Plinio y otros autores hasta la Antigüedad tardía. ${ }^{36}$ Esta equivocación influyó en todo el noreste de la península, puesto que se sabía que tanto el Ebro como Idubeda eran paralelos a los Pirineos, se extendían de norte a sur y "deformaban" en cierta forma la región (Figs. 2a-b). También Artemidoro de Éfeso, que había estado en Iberia igualmente, se hizo eco de esta falsa estimación, ${ }^{37}$ no solo en el segundo libro de sus Geographoumena, sino también en un papiro de reciente aparición que data de la última década del siglo II. En dicho papiro parafraseaba a todas luces su obra y la completaba con un bosquejo de mapa que no guarda ninguna relación con el texto. Asimismo, explicaba lo siguiente: "A la zona que va desde los Pirineos hasta las inmediaciones de Gadeira, junto con el interior, la llaman indistintamente Iberia o Hispania. Los romanos la han dividido en dos provincias: la primera provincia está formada por la región que se extiende desde la cordillera pirenaica hasta Carthago Nova y Castulo hasta el nacimiento del Baetis, y forman parte de la segunda la zona que llega hasta Gadeira y toda la región de Lusitania." 38 Su reproducción de las denominaciones de este territorio, la estructura política y las fronteras geográficas, ya fueran montañas, ciudades o regiones, ofrece por primera vez una sistematización para la que se requiere una elección, es decir una concepción del conjunto del espacio, y por tanto supone la primera visión coherente de Hispania. ${ }^{39}$

32 Plb., 3.59.7; al respecto PÉDECH 1964, 558-559; WALBANK 1979, 555-560.

33 Plb., 3.17.2; 10.7-15. Cruz ANDreotti 2006, 77-96, aquí 82; cf. Gómez Espelosín 2005, 113-139; GómeZ Fraile - Albaladejo Vivero 2012, 375-380.

34 Plb., 3.57.2-5; 34.5.12-14.

35 Plb., 3.37.9-11; 39.4-5; 34.5-9.

36 Sobre los motivos de esta estimación errónea y las repercusiones que tuvo en la noción de este espacio geográfico BeLtrán LloRis - Pina Polo 1994, 103-133.

37 Str., 3.1.4; STieHLe 1856, 193-244, frg. 13; Hagenow 1932.

38 P. Artemid. Kol. IV 1-14 se corresponde, salvo pocas excepciones, con STIEHLE 1856, 193-244, frg. 21; traducción de GaLlazZI - Kramer 1998, 189-208, aquí 197; véase también Kramer 2006, 97-114.

$39 \mathrm{Su}$ profundo conocimiento de la concepción geométrica del espacio se refleja también en la exactitud de las distancias indicadas, véase a ese respecto Moret 2012, 425-456; en general, MARCotTe 2010, 333-371; 


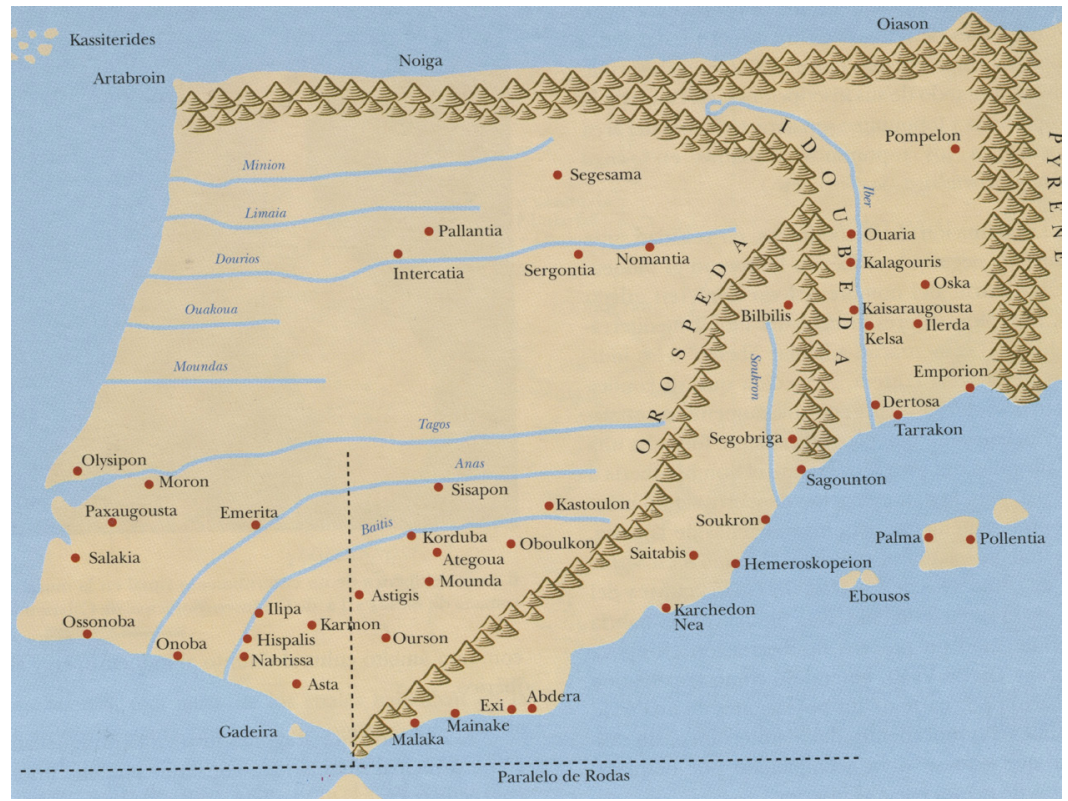

Fig. 2a. La confusión de Polibio reproducida también por Estrabón, que acarrearía graves consecuencias: los Pirineos están orientados de norte a sur, al igual que el Ebro y el sistema Central. Beltrán Lloris - Martín-Bueno - Pina Polo 2000, 17.

El análisis y la descripción del espacio que el viajado Estrabón (c. 63 a.C. - 23 d.C.) hace en sus Geographika están claramente influidos por las tradiciones literarias de sus principales fuentes (en particular, Eratóstenes, Polibio y Poseidonio), y también por criterios políticos e ideológicos, como su actitud general favorable a Roma y el principado. ${ }^{40}$ Por consiguiente, a pesar de su fecha de redacción, sus criterios se ceñían más bien a los de la República tardía. No obstante, su descripción de la "piel de toro", con la que compara a la Península Ibérica, más que una mera compilación es una "geografía de la civilización", es decir, aporta información sobre un territorio estructurado tanto por la administración como por las distintas etnias que lo poblaban. ${ }^{41}$ $\mathrm{Su}$ descripción tiene como objeto los logros de la romanización, los elementos de la infraestructura como el sistema de calles, las ciudades, su rango jurídico; los Pirineos y la vertiente de Idubeda orientada al agreste interior, considerado pobre, primitivo y segregado del resto y que albergaba una de las tribus más salvajes de Hispania, apenas sí reciben atención o únicamente comentarios negativos. ${ }^{42}$ Estas dicotomías (espacios de civilización y barbarie, centro y periferia), determinan en última instancia

RATHMANN 2011, 350-368.

40 Sobre esta forma de proceder van Der Vliet 1984, 27-86; TrotTa 1999, 81-99; Prontera 2011, $183-196$.

41 Str., 3.1.3. Cruz Andreotti 2007, 251-270.

42 Str., 3.4.10; 3.4.12-13; 3.4.15, cf. 3.3.7-8. 
el análisis cultural y geográfico que Estrabón hace de las Hispaniae. ${ }^{43}$ Por el contrario, Plinio el Viejo (23/24-79 d.C.), que entre los años 66 y 74 desempeñó el cargo de procurator Augusti en la Tarraconense, ofrece en su Naturalis historia en parte "una mera presentación de los nombres de las localidades con la obligada concisión"; pero esta le lleva al final a una descripción sistemática de la Península Ibérica, que resulta impresionante por su preciso conocimiento de la geografía política y la organización administrativa. ${ }^{44}$ Así, articula sus observaciones sobre las tres provincias comenzando por una descripción del paisaje y enumerando después los conventus o ciudades. Estas listas van seguidas, en un primer paso, de la descripción tradicional de la costa en forma de periplo, con excursos sobre los principales ríos y referencias a las etnias más importantes; sin embargo, en segundo lugar figura una descripción novedosa del interior, en tanto que se centra en las ciudades y, de ese modo, la presentación de las distintas regiones parte de sus centros políticos y administrativos. ${ }^{45}$

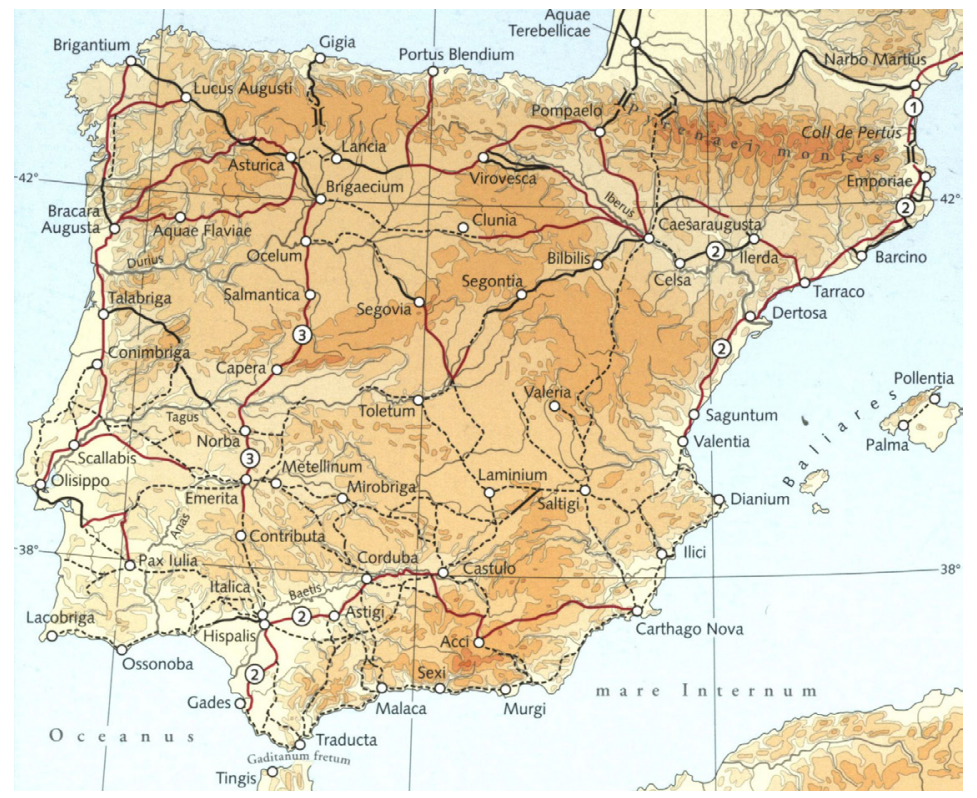

Fig. 2b. Orientación real de ambas cadenas montañosas y el Ebro.

Olshausen 2007, 199a.

\section{La actuación en el espacio}

Así pues, parece que el Senado romano tomó sus decisiones con este "mundo en mente", y por tanto también los imperatores, los gobernadores y los miembros de las comisiones senatoriales que Roma mandó a la Península Ibérica. Se puede observar

43 Cf. ENGELs 2007, 123-134.

44 Plin., nat. 3.2: locorum nuda nomina et quanta dabitur brevitate ponentur, claritate causisque dilates in suas partes; nunc enim sermo de toto est. NAAs 2002; Murphy 2004; Beltrán Lloris 2007, 115-160.

45 Beltrán Lloris 2006, 217-240; ID. 2012, 477-498. 
que la fundación de ciudades fue simultánea al comienzo de la presencia romana $\mathrm{y}$, en este sentido, resulta paradigmático el caso del noroeste, donde los hermanos Escipiones tomaron tierra en el año 218. La primera fundación dentro de esta zona fue Tarraco, ciudad que los Escipiones convirtieron en su centro estratégico. Estaba situada en la costa entre las alturas de los Pirineos y la desembocadura del Ebro, a 34 días de Roma, y para el castrum se aprovecharon tanto de una colina como de la cala que había formado el río Tulcis (Francolí). ${ }^{46}$ La ubicación sobre el arx facilitó el control de los amarraderos y las playas, por una parte, y de la vía Heraclea, por otra, mediante la que se comunicaba con el sur y el norte; y siguiendo el curso del Francolí, era posible llegar a la Meseta y al norte de la Península Ibérica por el valle del Ebro. Los iberos ya habían sabido valerse de esta posición geoestratégica destacada; desde la fundación de los Escipiones, el oppidum existente desde el siglo V a.C., probablemente llamado Kissa, Cissis o Ke(s)se, pasó a formar parte de Tarraco (Fig. 3). Pocas décadas después le siguió en el interior Gracchuris (Eras de San Martín, Alfaro - La Rioja), la ciudad de Tiberio Sempronio Graco. Fundada por este tras su victoria sobre la mayor parte de las tribus celtíberas en los años 180 y 178 , se localizaba entre el sistema Central y el Ebro, sobre una elevación natural y en el cruce de importantes vías de comunicación. Aquí confluían el Alhama, el Arga y el Aragón con el Ebro, de forma que podían controlarse los accesos en dirección a la costa y a los Pirineos o hacia la Meseta. ${ }^{47}$ Asimismo, esta ciudad fundada por Roma para que la poblaran indígenas, dotada de un eficiente sistema de defensa natural gracias a sus ríos, desfiladeros y terrenos pantanosos, en una zona fronteriza entre los pueblos vascos y celtíberos de la orilla sur del Ebro, se retrotrae a un poblado anterior, del siglo VIII en este caso: Ilurcis. Parece muy probable que el gobernador de la Hispania Citerior, Quinto Elio Peto, levantase un campamento fortificado nombrándolo Castra Aelia en el valle central del Ebro en el año 170, en el marco de los conflictos con los pueblos celtíberos que por lo visto Graco no consiguió pacificar. Puede que se ubicase en la zona de la desembocadura del río Jalón, en la orilla norte del Ebro, sobre una terraza fluvial (El Castellar-Valdeviñas - Torres de Berrellén), lugar que parece ideal para un destacamento militar, ya que el Jalón no solo constituía una vía de comunicación con el territorio celtíbero, sino también con la Meseta, de forma que era posible avanzar hasta el valle del Tajo (Tagus). Pero también podría haber estado en la ribera derecha, $17 \mathrm{~km}$ río abajo del establecimiento augusteo de Caesaragusta (La Cabañeta - El Burgo de Ebro, Zaragoza), extendiéndose en forma de rectángulo sobre una superficie de 21,4 ha, con tres de sus lados protegidos por una fosa de unos $30 \mathrm{~m}$ de an-

46 Plin., nat. 3.21; Mela, 2.90; Liv., 27.7.1 transmite la duración de la ruta marítima; esta no se redujo a cuatro días (Plin., nat. 19.4) hasta que las Baleares estuvieron bajo dominación romana a partir de finales del siglo II a.C., proporcionando una escala segura para la navegación (Str., 3.5.1). - ALFöLDY 1978, 570-644; Panzram 2002, 23-127; Dupré Raventós 2004.

47 Fest., p. 97, (72) (Ed. C.O. Mueller): Gracchuris urbs Iiberae regionis, dicta a Graccho Sempronio, quae antea Ilurcis nominabatur; Liv., per. 41: Tib. Sempronius Gracchus pro cos. Celtiberos victos in deditionem accepit, monumentumque operum suorum Gracchurim oppidum in Hispania constituit; (...); Plin., nat. 3.24. Hernández Vera 2002, 173-182; García Fernández 2009, 215-230. 
cho. ${ }^{48}$ En cualquier caso, el campamento militar pasó a ser un oppidum en las décadas posteriores, y siguió estando habitado fundamentalmente por itálicos. Alrededor de tres décadas más tarde, Décimo Junio Bruto fundó la ciudad costera mediterránea de Valentia (Valencia) en el año 138, tras el fin de la guerra contra los lusitanos. ${ }^{49} \mathrm{Va}$ lentia quedaba a media distancia entre Tarraco y Carthago Nova, prácticamente en la desembocadura del río Turia, muy cerca del oppidum ibérico Kili y tampoco lejos de Arse (Sagunto) y Saiti (Játiva), y fue el lugar donde Bruto alojó a sus veteranos. La ciudad no solo controlaba la vía Heraclea, sino que evolucionó hasta ser un puerto decisivo en la guerra contra Numancia.

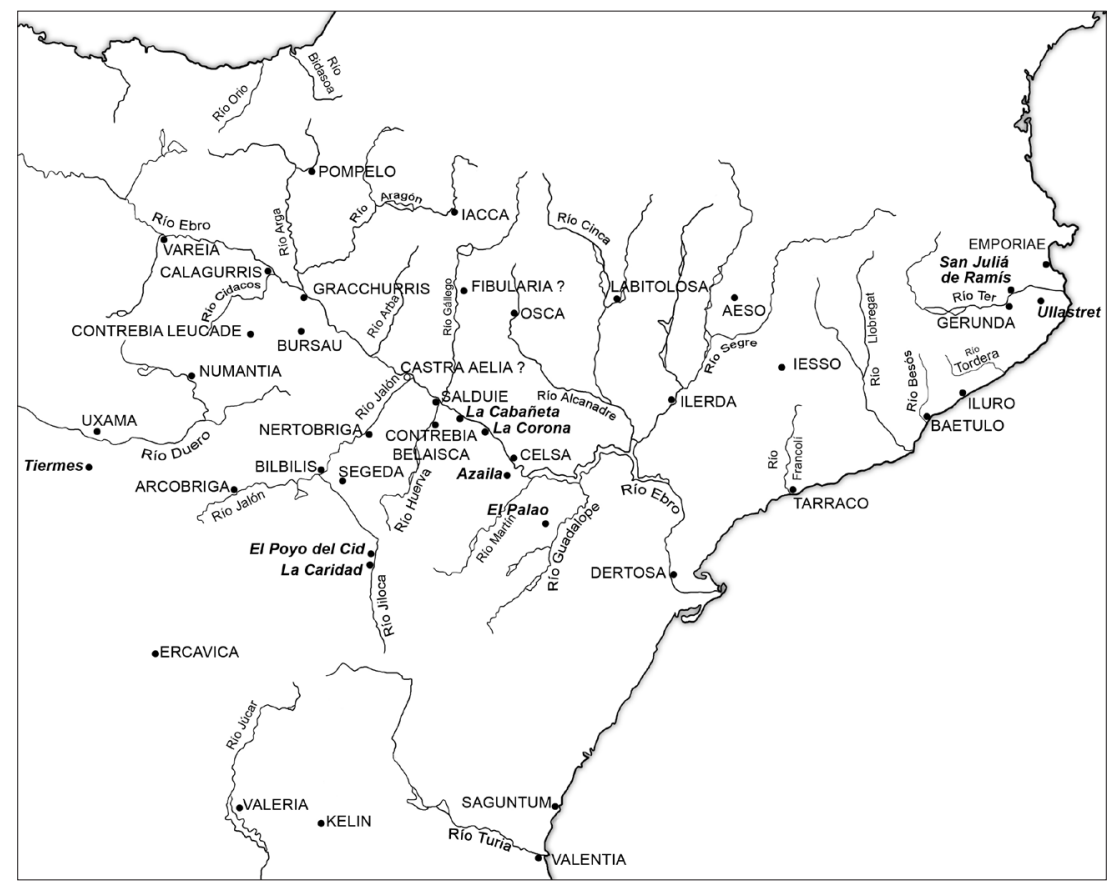

Fig. 3. El noreste de Hispania: asentamientos nativos y fundaciones romanas.

Pina Polo 2007, 56 fig. 2.

48 Liv., per. 91; Liv., frg. 91.3; 10; 12; Plu., Sert. 16.1; Sall., Hist. 2.93. Pina Polo - Pérez CaSAs 1998, 245-264, proponen una localización de Castra Aelia en El Castellar-Valdeviñas a partir de un análisis exacto de la transmisión literaria. Ferreruela Gonzalvo - Mínguez Morales 2002, 205-214; ID. 2003, 247-262, utilizan los restos arqueológicos para argumentar la ubicación en La Cabañeta; cf. también OLCOZ YANGUAS - Medrano MarquÉs 2006, 55-75, que se decantan en favor de Fitero (Navarra).

49 Liv., per. 55.4: Iunius Brutus cos. in Hispania is, qui sub Viriatho militaverant, agros et oppidum dedit, quod vocatum est Valentia; Diod., 33.1.3; App., Ib. 71-73; Plin., nat. 3.20. RiBera I LACOMBA 2002, 299-313; ID. 2006, 75-89. 
Tras el final de la guerra, por tanto en torno al término del siglo II y el primer cuarto del siglo I, surgieron nuevos asentamientos urbanos en el área de la costa o el interior más próximo a esta, y en la región premontañosa de los Pirineos, a los que solo podremos referirnos a continuación con algunos ejemplos. En el litoral mediterráneo, en la parte sur de la bahía de Roses, se estableció Emporiae (Ampuries), una ciudad cuyos orígenes se remontan al primer campamento militar que Roma levantó en suelo hispano, manteniendo probablemente la debida distancia con los indigetes allí asentados hasta ese momento y una colonia griega del siglo VI. La nueva ciudad contaba con una superficie de 20,5 ha en forma de rectángulo alargado, foro y termas, y estaba rodeada por una muralla. ${ }^{50}$ Gerunda (Girona) estaba emplazada en las estribaciones de Las Gavarras, en la confluencia del Galligants y el Oñar, poco antes de su desembocadura en el Ter, sobre la vía Heraclea. ${ }^{51}$ Desde esa localización, el asentamiento tenía una buena visión panorámica de los vados de los ríos y, por tanto, de las vías de comunicación y comerciales en dirección norte-sur y este-oeste; el control de la zona lo habría tenido hasta ese momento y probablemente desde el siglo VI el oppidum ibero de Sant Julià de Ramis (*Kerunta), situado a $5 \mathrm{~km}$ de distancia sobre una cima y con una extensión de 3 a 4 ha. La creación de una nueva ciudad con unas dimensiones de entre 5 y 6 ha sorprende también porque la pendiente parece poco propicia tanto para su sistema de calles ortogonal, en el que la vía Heraclea hacía de cardus maximus, como para su dotación arquitectónica "a la romana" del lugar alzada sobre tres terrazas. Iluro (Mataró, Barcelona) también se fundó en una posición estratégica ideal, pues se extendía sobre una elevación junto a la costa, a una distancia de unos $400 \mathrm{~m}$ del litoral actual, con una superficie de 7 ha estructurada conforme al sistema ortogonal. ${ }^{52}$ Ello facilitaba que desde el asentamiento se avistasen los accesos hacia el interior, si bien no todo lo bien que había sido posible hacer anteriormente desde el oppidum de Burriac, situado a 4,5 km al noreste. El poblado más significativo de los Laietani, cuyos orígenes se remontan al siglo VI, tenía 7-10 ha de extensión y se encontraba en la parte costera de la mayor montaña del valle de Cabrera de Mar. A solo $20 \mathrm{~km}$ al sur de Iluro se fundó Baetulo (Badalona, Barcelona), también sobre una colina cercana a la costa y con forma rectangular, aunque con unas dimensiones de 11 ha. En este caso, la topografía apunta a una división bipartita de la ciudad amurallada. El foro y los edificios del atrio probablemente estuviesen en la pendiente, mientras que las termas y las tabernae se encontrarían en la parte llana, zona esta última por la que más adelante pasaría la vía Augusta. Baetulo también se encontraba cerca de un oppidum: la población ibera Turó d'en Boscà, asentada sobre una colina desde el siglo IV, a tan solo 2,4 km de distancia. ${ }^{53}$ En la región premontañosa de los Pirineos se fundaron al mismo tiempo otras ciudades, como por ejemplo Iesso (Guissona, Lleida), localizada en el altiplano central de la actual Cataluña, a unos $80 \mathrm{~km}$ de de la

50 Liv., 34.9; Str., 3.4.8; Mela, 2.89; Plin., 3.22. Mar Medina - Ruiz de Arbulo Bayona 1993; AquiluÉ ET ALII 2006, 18-31; AquILUÉ ABADÍAs 2012.

51 Plin., 3.23. - Burch et alII 2010, 119-127; Nolla Brufau et alit 2010.

52 Mela, 2.90; Plin., nat. 3.22. Clariana i Roig 2001, 19-52; Martín MenÉndeZ - García Roselló 2002 , 195-204; GUITART i Duran 2006, 51-61.

53 Mela, 2.90; Plin., nat. 3.22. Guitart - Padrós 1990, 165-177; Comas i Solà - Surroca i Coretv 2006, 51-61. 
costa y a $40 \mathrm{~km}$ de las estribaciones de los Pirineos. ${ }^{54}$ Es probable que su extensión en forma de polígono irregular abarcase un territorio de $18 \mathrm{ha}$; su predecesora ibérica pudo haber sido el oppidum de Puig Castellar de les Guixeres de Taltatüll (Biosca, Lleida), situado a $6 \mathrm{~km}$ a orillas del río Llobregós. El proceso seguido para las nuevas fundaciones de Aeso (Isona, Lérida) ${ }^{55}$ e Ilerda ${ }^{56}$ o incluso Labitulosa (La Puebla de Castro, Huesca) ${ }^{57}$ podría haber sido comparable estructuralmente.

A finales de los años 90, Cayo Valerio Flaco, gobernador de Hispania Citerior, tras su victoria contra los celtíberos fundó en el año 93-92, en una lengua de roca caliza a unos $1.000 \mathrm{~m}$ de altura, sobre los desfiladeros de los ríos Zahorra y Gritos, la ciudad de Valeria (Valera de Arriba, Cuenca). ${ }^{58}$ Este asentamiento para indígenas de la frontera sur de Celtiberia, al que el gobernador romano dio su nombre, hacía las veces, al igual que su predecesora de la Era de Bronce, de nudo de comunicación de la Meseta oriental con el sur y con la costa, es decir, con la ciudad portuaria de Valentia. Allá por el año 72-71, tras el fin de la guerra contra Sertorio, Pompeyo también erigió una ciudad con su nombre para las etnias locales, entre ellas los vascones, que adquirirá importancia estratégica. Se trataba de Pomp(a)elo (Pamplona), ubicada en una elevación del río Arga, junto a la ruta que unía el valle del Ebro por el paso Lepoeder con la futura provincia Galia Aquitana..$^{59}$ Marco Emilio Lépido no fue menos que Pompeyo y en el año 43-42 fundó la colonia Victrix Iulia Lepida Celsa (Velilla de Ebro, Zaragoza $)^{60}$ en la orilla norte del Ebro, en las inmediaciones del oppidum ibérico de Kelse. Esta fue la primera colonia de ciudadanos romanos en el valle del Ebro central y la segunda de todo el noreste peninsular, puesto que Tarraco obtuvo este estatus poco antes que ella. La ubicación a orillas del Ebro no solo le facilitaba el uso de la vía fluvial navegable hasta Vareia (Logroño), ${ }^{61}$ sino también el control del paso, que se manifestaba en el único puente de piedra existente en la región; además, la colonia estaba conectada con la calzada que iba de Tarraco a Ilerda. No obstante, cuando Augusto fundó Caesaraugusta (Zaragoza) a solo $50 \mathrm{~km}$ río arriba alrededor de tres décadas después, estas ventajas resultaron no ser tales, puesto que la ciudad fue abandonada ya en el 60 d.C. En cualquier caso, el princeps fundó la colonia de Caesaraugusta durante su segundo viaje a Hispania en torno al año 15 d.C., en el lugar en el que parece que había estado Salduie, el oppidum de los Sedetani, desde la segunda mitad del siglo III, en la confluencia del Ebro, el Huerva y el Gállego, allí donde se unen los caminos naturales y los ejes de las calzadas. ${ }^{62}$ Por tanto, se en-

\footnotetext{
54 Plin., nat. 3.23. Pera ISERn 1997, 229-236; GuITART i Duran 2006, 51-61, sobre todo 55-59.

55 Plin., nat. 3.23. ChASSEIGNE ET ALII 2006, 146-158, sobre todo 147-148.

56 Payà Mercé et alit 1996, 119-149; Gil et alit 2001, 161-174; Payà Mercé 2004, 323-324.

57 Chasseigne ET ALII 2006, 146-158, sobre todo 151-156; Magallón Botaya - Sillières 2013.

58 App., Ib. 100; Plin., nat. 3.25. Fuentes Domínguez 1997, 103-132; Gozalbes Cravioto 2009; ID. 2012, $161-200$

59 Sall., Hist. 2.93; Str., 3.4.10; al respecto, en concreto sobre la problemática planteada por la interpretación de la transmisión escrita Pina Polo 2009, 195-214; vgl. Amela Valverde 2000, 7-41, esp. 10-20.

60 Str., 3.4.10; Plin., nat. 3.24. Beltrán Lloris 1990, 179-204; García-Bellido 2003, 273-290; Beltrán Lloris - Mostalac CARrillo 2008, 107-127.

61 Plin., nat. 3.21.

62 Str., 3.4.10; Plin., nat. 3.21. Fatás Cabeza - Beltrán Lloris 1997; Beltrán Lloris - Fatás Cabeza 1998; BELTRÁN LLORIS 2007.
} 
contraba en el centro de la región situada entre los Pirineos y el sistema Central que puede considerarse un "trifinio paleohispánico" por la coincidencia de tres culturas: la ibera en el este, la celta en el oeste y la vascona al norte. ${ }^{63}$ Augusto convirtió a la única ciudad del Imperio que llevaba su nombre y estaba destinada a los veteranos de las guerras contra los astures y los cántabros, entre otras, en la capital del conventus Caesaraugustanus y dispuso que fuese el centro de una serie de ciudades privilegiadas como Bilbilis (Calatayud), Celsa (Velilla de Ebro) y Calagurris (Calahorra).

\section{Fundación de ciudades y aprehensión del espacio}

Los representantes de Roma no solo se vieron confrontados con distintas etnias, sino también con distintas formas urbanas en el noreste de la Península Ibérica. ${ }^{64} \mathrm{Si}$ bien los asentamientos habitados por los Indigetes, Ausetani, Laietani, Ilergetes, Seditani, Berones y otros pueblos se distinguían entre sí por su grado de urbanidad y su forma de organización sociopolítica, desde la perspectiva de Grecia y de Roma todos se consideraban "ciudades" por igual. Así, Polibio se refiere a Carthago Nova como una polis, ${ }^{65}$ y Livio llama a Saguntum en distintos contextos civitas, urbs u oppidum indistintamente, pero con plena consciencia de que cumplía con ciertos requisitos que la diferenciaba, por ejemplo, de un castellum ${ }^{66}$ Las medidas adoptadas durante los dos primeros siglos de presencia romana con respecto al mundo urbano preexistente tuvieron que ver con la progresiva ocupación de territorios y se manifestaron, por un lado, en la conquista y la destrucción de ciudades y, por otro lado, en la fundación o refundación de otras. Las destrucciones se escapan a nuestro conocimiento, aunque también es de suponer que los generales diesen cuenta de ellas en los informes que presentaban al Senado romano, al igual que del número de prisioneros capturados. De ello tenemos noticia solo de forma indirecta, cuando tuvieron como consecuencia la reubicación de la población que se había opuesto a Roma y había sido castigada por ello con el desarraigo y una socialización según los parámetros romanos. Tales medidas iban acompañadas de la confiscación de tierras y podían llevar a una "reordenación" literal de las relaciones de propiedad reinantes. ${ }^{67}$ En cuanto a las fundaciones y refundaciones de ciudades parece que en un primer momento solo se produjo un número reducido, según refleja la transmisión: Tarraco, Gracchuris, Castra Aelia, Valentia, Emporiae, Valeria, Pomp(a)elo y Celsa-ocho asentamientos urbanos en el noreste, otros siete en el resto de la Península Ibérica (Italica [Sevilla], Carteia [San Roque], Iliturgi [Mengíbar], Corduba [Córdoba], Brutobriga [?]) incluyendo las islas (Palma [Palma de Mallorca], Pollentia [Alcúdia]). Al cotejar esta información con los hallazgos arqueológicos excavados en las últimas tres décadas, esta cifra aumenta

63 FAtÁs CABEZa 1998, 29-50; cf. también Beltrán Lloris ET ALII 2000.

64 Al respecto Asensio EstebÁn 1995; Marco Simón 2003; Domínguez Monedero 2005, 119-127 y 285 292.

65 Plb., 3.17.2; 10.7-15; cf. Str., 3.4.13.

66 civitas: Liv., 21.7.2; 7.4; 8.7-8; urbs: 21.14.2; 8.6; 15.1; oppidum: 24.42.9; castellum: Liv., 34.11.2; 40.33.9; 47.2; al respecto véase a Le Roux 1999, 233-250; BedON 2003, 229-263.

67 Pina Polo 2004, 211-246, concretamente 230-246; ID. 2011, 39-53, concretamente 46. 
considerablemente, por lo que ahora cabe suponer que la organización del territorio y del universo urbano no se caracterizaron por la continuidad, sino por la transformación y el cambio. En cualquier caso, nuestro conocimiento sobre estos procesos sigue siendo muy limitado debido al estado fragmentario de las fuentes sobre la época; de pocas fases de la historia urbana de la Península Ibérica disponemos de un número tan escaso de testimonios como de la época republicana, motivo por el que todo intento de emitir una afirmación al respecto termina siendo una búsqueda de huellas.

Los retazos esbozados en este contexto sobre las fundaciones del noreste pueden sistematizarse de distintas formas. Desde el punto de vista cronológico, se observan tres fases: las últimas décadas hasta la caída de Numancia, en la que los imperatores tomaron la iniciativa, seguida de 40 años en los que no es posible identificar con claridad a los artífices de los cambios, y por último otra etapa en la que desarrollan su actividad los gobernadores o los protagonistas de las guerras civiles hasta Augusto. La actividad fundacional de los Escipiones, Graco, Paeto y Bruto estuvo claramente relacionada con episodios bélicos y obedeció a una necesidad concreta; las ciudades se situaron en puntos de importancia geoestratégica, si bien los fundadores se guiaron por los poblados indígenas para escoger los emplazamientos o, al menos, casi todas las ciudades se establecieron sobre poblados indígenas. Tras la conquista de Numancia cambió el procedimiento, y se fundaron una serie de nuevas ciudades en el litoral mediterráneo y en el Prepirineo, sin que se haya conservado rastro de los responsables de su creación. Las nuevas ciudades surgieron a muy poca distancia de sus asentamientos predecesores; utilizaron la posición destacada de estos, que a menudo les había permitido controlar las vías de tránsito y comercio por su localización elevada. Con respecto a su tamaño no eran mucho más grandes, y asimilaron a veces el topónimo y grosso modo su población. En la mayoría de casos su espacio estaba estructurado siguiendo un sistema ortogonal y experimentaron un desarrollo arquitectónico "a la romana", al menos allí donde es posible comprobarlo; excepciones como Baetulo confirman la norma. A largo plazo su creación provocará el abandono de los antiguos asentamientos.

No es posible relacionar de forma convincente estas fundaciones urbanas con acontecimientos militares, sino que más bien parece que fueron las consecuencias de ellos. En efecto, Roma envió en el año 133 una comisión senatorial de diez miembros a la Península Ibérica, pues era la primera vez desde que estaban allí presentes hacía casi un siglo que cabía esperar la victoria militar definitiva con la caída de Numancia. ${ }^{68}$ Sus dominios comprendían hasta ese momento toda la costa mediterránea, el área central del valle del Ebro, el alto Tajo, el valle del Guadalquivir y la región entre este río y el Guadiana; tras la victoria sobre los celtíberos y los lusitanos este territorio casi se duplicó, con la incorporación de toda Lusitania, el sur de la Gallaecia, la mayor parte de la Submeseta Norte y el alto Duero. Estaba claro que la reestructuración era necesaria. El envío de la comisión daba muestras de un cambio de conducta notable por parte del Senado; hasta la fecha se había delegado este tipo de decisiones en el gobernador, mientras que ahora los senadores intervenían directamente sobre

68 App., Ib. 99; al respecto Le Roux 1995, 49; Richardson 1996, 87-88; Pina Polo 1997, 83-104. 
el terreno junto con los imperatores y, en cierto modo, autorizaban sus actuaciones. ${ }^{69}$ Apiano, único autor gracias al que nos consta esta comisión senatorial, cuenta también que Escipión Emiliano destruyó Numancia hasta sus cimientos, repartió sus territorios, castigó a sus aliados y escogió a 50 numantinos para la entrada triunfal que Roma le concedió a su regreso en el año $132 .{ }^{70}$ No menciona Apiano más medidas, sino que constata únicamente que los decemviri debían dedicarse a organizar las zonas que Décimo Junio Bruto y Escipión Emiliano habían añadido al Imperio, una vez pacificadas. Lo más probable es que sus actividades estuviesen relacionadas con los territorios de reciente incorporación. ${ }^{71}$ Esta afirmación excluye la posibilidad de una reorganización de toda la Península Ibérica, o al menos en forma de una lex provinciae, como se ha postulado en distintas ocasiones. ${ }^{72}$ No obstante, puede puntualizarse proponiendo que estas medidas con toda certeza ejercieron una influencia palpable en otras regiones de la Península Ibérica, como el noreste; y lo mismo cabe decir sobre las medidas tomadas por la comisión enviada en el año 95 (pues, en contra de lo que había pensado el Senado, no pasaron ni veinte años hasta que volvieron a estallar los conflictos militares). ${ }^{73}$

Por tanto, Roma habría sido responsable de los cambios observables en esta época dentro del ámbito urbano. ¿Pero cómo se ha de entender su influencia? Nathalie Barrandon ha contestado a esta pregunta con rotundidad no hace mucho: con su mera presencia. ${ }^{74}$ Además, no ve ninguna política de reestructuración del territorio; si Roma la hubiese deseado, habría promulgado una lex provinciae. Como máximo, sus representantes intervinieron de forma activa puntualmente, reaccionando en cuanto las élites locales actuaron. No obstante, en este caso no existió tal necesidad, porque la iniciativa de refundación de asentamientos habría partido de la propia población que los habitaba. En cambio, José Ángel Asensio Esteban ya constató en su momento paralelismos con las ciudades fundadas por aquel entonces en la Península Itálica a partir de criterios urbanísticos, y Francisco Pina Polo postuló un cierto "intervencionismo" de Roma, en particular aludiendo a la red de calzadas construida en esa región durante la época de Augusto, que casi con toda probabilidad seguía, al menos en parte, el trazado de las redes de comunicación locales; por ejemplo, Valentia, Tarraco, Baetulo, Iluro y Gerunda se ubicaban junto a la vía Augusta, e Ilerda y Pomp(a) elo en la calzada que unía Tarraco y Oidasun (Oyarzon) y por ende, el Mediterráneo y el Atlántico. ${ }^{75}$ De hecho, ampliando más la perspectiva, es decir, teniendo en cuenta la tercera fase fundacional, en la que intervinieron los gobernadores o los protagonistas de las guerras civiles hasta Augusto, se demuestra que todas estas fundaciones siguen

69 Fundamental al respecto es SCHLEUSSNER 1978, 9-100.

70 App., Ib. 98; Vell. Pat., 2.4; Liv., per. 59. Sobre el orden de cada una las medidas PinA PoLo 1997, 83104, esp. 92-93.

71 App., Ib. 99. - Así KNApp 1977, 78 y 84; Richardson 2004, 156-157; CurCHin 1991, 40-42.

72 En este sentido se ha pronunciado, por ejemplo, SALINAS DE Frías 1995, 42-47; en contra LinTOTT 1993, 28-32; KALlet - MARX 1995, 18-30, quienes dudan de que semejante lex provinciae haya existido.

73 Pina Polo 1997, 83-104, concretamente 98; ID. 2003, 155-158; AsENSIO EstebAn 2003, 159-178.

74 BARRANDON 2011.

75 Asensio Esteban 2003, 159-178. - Str., 3.4.10; así Pina Polo 2007, 25-57, esp. 29-31, resp. ID. 1993, 77-94, esp. 90-94; véase también ARIÑo GIL ET ALII 2004, 117-138. 
un modelo. Con ello no nos referimos al motivo concreto, otra vez en el contexto de la finalización de conflictos bélicos, en este caso con los celtíberos, para alojar a la población indígena o a los veteranos en lugares destacados, ni a la práctica tradicional de hacerlo en ciudades nombradas según el líder militar para glorificar sus victorias, sino al hecho de que la aprehensión del espacio tuviera lugar a través de estas fundaciones.

La coincidencia entre el avance de la aprehensión del espacio y la ubicación de ciudades se manifiesta especialmente al intentar sistematizarlas atendiendo no sólo a la cronología sino también a su ubicación geográfica: Roma fundó en primer lugar una ciudad portuaria, Tarraco, y una en el interior, Gracchuris, que en ese momento prácticamente jalonaba el extremo del espacio conocido en el valle del Ebro, y por último a media altura y también en la vía de tránsito del Ebro, Castra Aelia. La creación de Valentia supone una vuelta a la costa, en la que a continuación surgirán una serie de asentamientos, comenzando por Emporiae, el primer embarcadero de las legiones, en un lugar conocido y pacificado desde hacía un siglo. Mientras tanto, se siguió avanzando hacia el interior y con la anexión del Prepirineo. Esta forma de proceder se repetirá en la República tardía con la fundación de Valeria y Pomp(a)elo, situadas en los extremos de la zona de influencia romana, antes de que, con cierta vacilación en el caso de Celsa y definitivamente en el caso de Caesaraugusta, fuesen escogidos lugares que demuestran que el uso de esta vía fluvial, y por tanto el conocimiento del terreno entre la costa y Vareia como último puerto fluvial, estaban ya tan avanzados que se pudo elegir un lugar central en el propio valle del Ebro. El análisis desde esta perspectiva hace aflorar un modelo que refleja qué "mundo" se tenía "en mente"; y en vista de la gran cantidad de normativas que regulaban el sistema político de la República tardía, según las cuales la construcción de murallas o la destrucción de una ciudad no podían tener lugar hasta contar con la aprobación del Senado ${ }^{76}$ debemos concluir que no solo es que estas nuevas fundaciones no pudieran haberse llevado a cabo sin el conocimiento de Roma, sino que puede que fuesen iniciadas por su parte: independientemente de las medidas de reestructuración de la comisión del Senado, pero sí con motivo de su actuación, que se correspondía con la nueva línea del Senado. Con seguridad hay que partir de una urbanización planificada, pero no en el sentido de que Roma actuase siguiendo un mapa, como el del papiro de Artemidoro, por ejemplo, sino sobre el terreno.

\section{Saber y conocimiento, control y geometría}

Por lo que respecta a la fundación de ciudades, Augusto también obró con la cautela que lo caracterizaba. Es conocido por su política urbana sistemática y completa, por una política de colonización y derechos civiles con la que en muchos aspectos daba continuidad a los imperatores de la República tardía (por ello muy a menudo no se puede saber con exactitud si la fundación de una colonia o un municipio se remonta a Augusto o a César), pero por otra parte su política también tuvo su propio estilo. ${ }^{77}$

76 App., Ib. 98 resp. 44.

77 Al respecto BleicKen 1999³, 452-471; KIENAST 20094, 450-515; cf. VitTINGHOFF 1952. 
Así los aspectos estratégicos, junto con el abastecimiento de sus veteranos, cobraron más relevancia que, por ejemplo, la política de la clientela. Cuando fundó Caesaraugusta en el contexto de su segundo viaje a la Península Ibérica, ${ }^{78}$ Roma llevaba más de un siglo de presencia en el valle del Ebro; sus representantes locales ya conocían la región lo suficientemente bien como para saber qué zonas eran adecuadas para fundar asentamientos, qué vías de comunicación tenían importancia decisiva y qué élites locales eran reacias a cooperar. Sus representantes lo asesoraron según sus conocimientos y le advirtieron sobre las desventajas de la fundación de Lepidus, de la posición demasiado "excéntrica" de Celsa para controlar los territorios del valle del Ebro y sobre las ventajas de Salduie, donde, por ejemplo, a finales de los años 90 a.C. ya se habían reclutado y embarcado caballeros de las poblaciones situadas $200 \mathrm{~km}$ a la redonda para la turma Salluitana. ${ }^{79}$ También el nombramiento de Caesaraugusta como capital del conventus Caesaraugustanus en el marco de la reorganización administrativa de las provincias hispanas pudo haberse basado en los conocimientos adquiridos localmente.

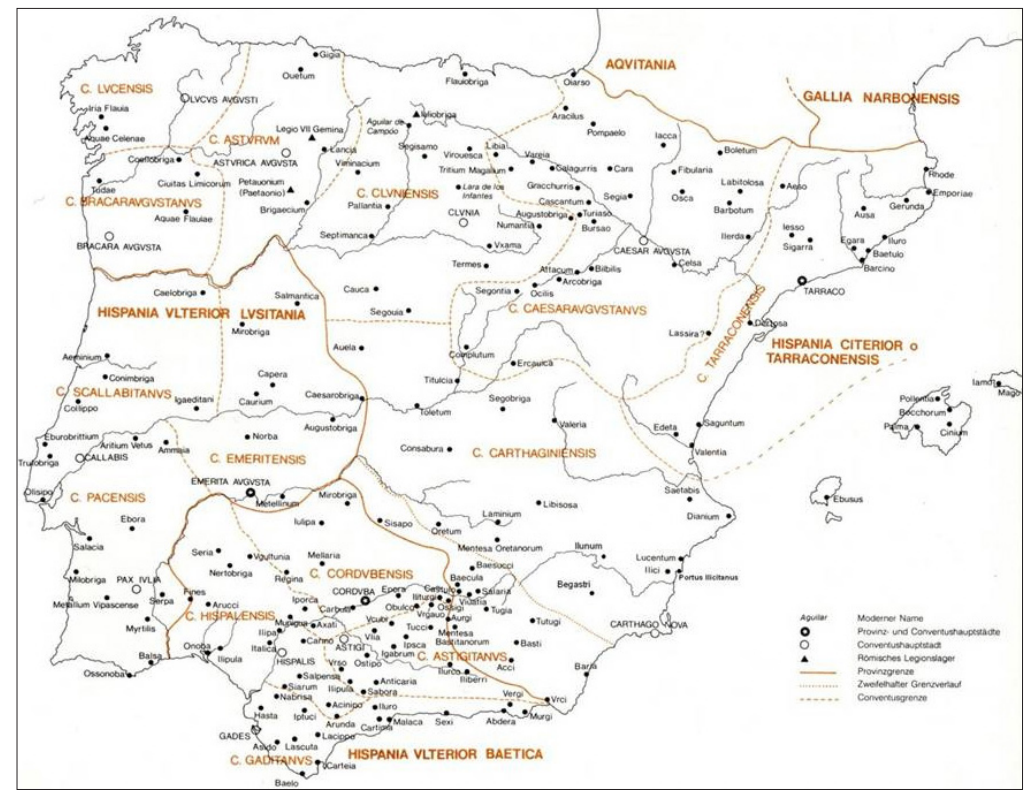

Fig. 4a. Organización administrativa de Hispania a comienzos del Imperio. Koch 1993, 31 fig. 3.

En efecto, durante la segunda mitad del siglo I a.C. aumentaron las explorationes; las empresas comerciales privadas, las misiones oficiales o las expediciones militares que viajaban en el nombre de Roma ya no descubrían nuevos territorios, sino

78 Abascal Palazón 2006, 63-78; ID. 2011, 289-317; fundamental para la práctica de gobernar viajando es el trabajo de HaLfmann 1986.

79 CIL I², 709; al respecto PINA Polo 2003, 197-204. 
que exploraban los ya conocidos. ${ }^{80}$ Así, el "saber sobre el espacio" experimentó un avance considerable en lo que respecta a la topografía y la estimación de distancias, así como a los conocimientos geometrico-astronómicos. En este aumento del "knowledge" frente a la "ignorance", Norman J. E. Austin y N. Boris Rankov vieron con acierto una de las diferencias decisivas entre la República tardía y el comienzo del Principado. ${ }^{81}$ La medición de la tierra y el trazado de fronteras sobre mapas actuales sugieren que Augusto se hubiese decidido a imponer el orden de la geometría al caos que sembraron las guerras civiles. Dicha afirmación es válida, sobre todo, para la Península Itálica, a la que dividió en once regiones asignándoles un número (Figs. 4a-b). ${ }^{82}$ Sin embargo, la comparación con el conocimiento del espacio de Estrabón muestra que en el caso del conventus Caesaraugustanus, el princeps se guió tanto por las estructuras maduradas como por otros criterios, tal y como reflejan sus Geographika (Fig. 5) ${ }^{83}$ En principio se produjo una legitimación de la situación preexistente, aunque esta práctica no se caracterizó por la homogeneidad, sino por la diversidad derivada de la multiplicidad de etnias y por tanto las distintas estructuras de pertenencia. La demarcación de fronteras y la geometría, por ende, sirvieron como medio de integración.

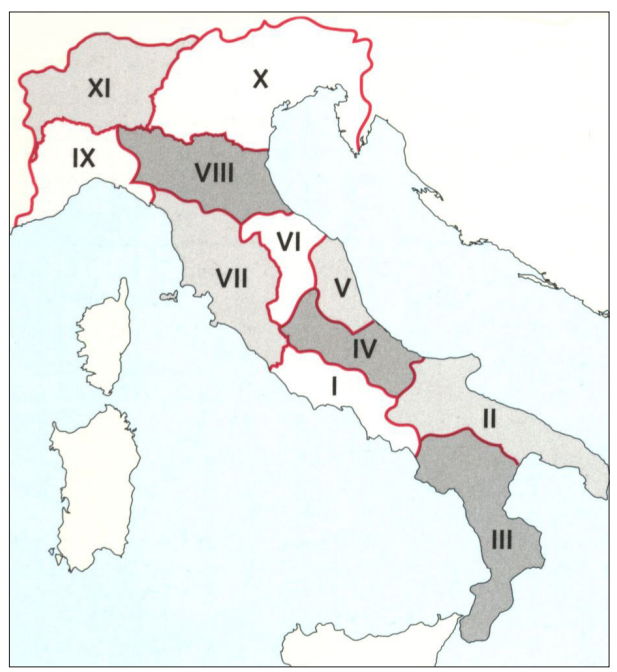

Fig. 4b. División de la Península Itálica en once regiones.

Olshausen 2007, 175a.

80 Al respecto NiCOLET 1988, 97-101.

81 Austin - Rankov 1995, 108: "It was ignorance, not knowledge of the world which she tried to conquer that was most characteristic of Republican Rome." Véase también WaLlace-HadRILL 2005, 55-84.

82 Bleicken 199933, 455-456; Kienast 20094, 480-481; cf. también NiCOLET 1991, 73-97.

83 OzCÁRIz Gil 2012, 557-579, y Dopico Caínzos - Santos Yanguas 2012, 581-600, siguen esta misma línea sobre el resto de conventus, en contra de las teorías antiguas que postulaban una demarcación fronteriza arbitraria como, por ejemplo, MACKIE 1983, 8. 
Que la decisión basada en este horizonte de experiencia fue la adecuada lo demuestran tanto el abandono de Celsa como la pervivencia y la importancia de Caesaraugusta en calidad de centro de la región hasta la época de los árabes. La ciudad era impresionante por su diseño constructivo, la regularidad de sus 44 ha de extensión ${ }^{84}$ la representación de sus élites sociales no solo en el concilium provinciae de Tarraco ${ }^{85}$ sino también en la aristocracia imperial ${ }^{86}$ y finalmente, porque fue la única del conjunto de las ciudades hispanas que aportó 18 mártires. ${ }^{87}$ Pero esta evolución no podía preverse todavía en época de Augusto, el princeps solo pudo contribuir como tal con la actividad fundacional. Sin embargo, era plenamente consciente de que el orbis terrarum sobre el que dominaba no solo debía ser medido, sino también dibujado, pues era la única forma de presentarlo de forma influyente.

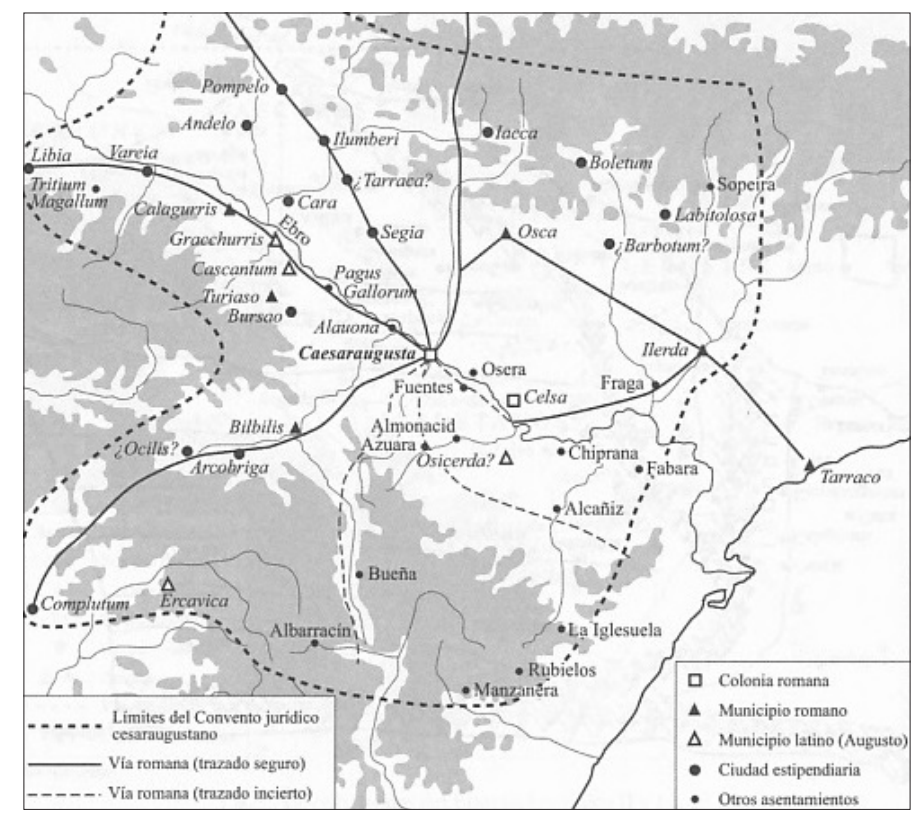

Fig. 5. El convento jurídico cesaraugustano.

Beltrán Lloris 2006, 235 fig. 1.

De hecho, la cartografía romana procede de la necesidad de visualizar el lugar de una victoria: Publio Sempronio Sofo ordenó la construcción de un templo en honor a Tellus cuando triunfó sobre los picenos en cumplimiento de su promesa, y adornó sus paredes con un mapa de la Península Itálica. ${ }^{88}$ Tiberio Sempronio Graco colocó

84 Beltrán Lloris - Fatás Cabeza 1998; Beltrán Lloris 2007; Escribano PaÑo 1998.

85 Flamines: CIL II ${ }^{2} / 14,1128$; $C I L \mathrm{II}^{2} / 14$, 1143; CIL II²/14, 1158; CIL $\mathrm{II}^{2} / 14,1160$.

86 Caballeros: $C I L I^{2} / 14,1128$; $C I L I^{2} / 14,1160$; senadores: CABallos RuFINO 1990, nº 78/p. 146-148.

87 Prud., perist. 4.

88 Varro, rust. 1.2.1; al respecto NiCOLET 1988, 109-110; Dilke 1987, 201-211. 
una forma de Cerdeña (probablemente un mapa con escenas pintadas) en el Templo de Mater Matuta, como memoria de su victoria sobre los cartagineses, en el año 174 a.C. ${ }^{89}$ Lucio Hostilio Mancino, comandante de la flota romana contra Carthago en el 148 a.C., expuso un plano de esta ciudad en el foro. ${ }^{90}$ También en los desfiles triunfales se mostraban tablas para engrandecer la fama de los héroes vencedores en forma de "spectacle géographique". ${ }^{91}$ Augusto continuó esta tradición y celebró su victoria con un mapa tan grande, exacto y completo como nunca antes había habido.

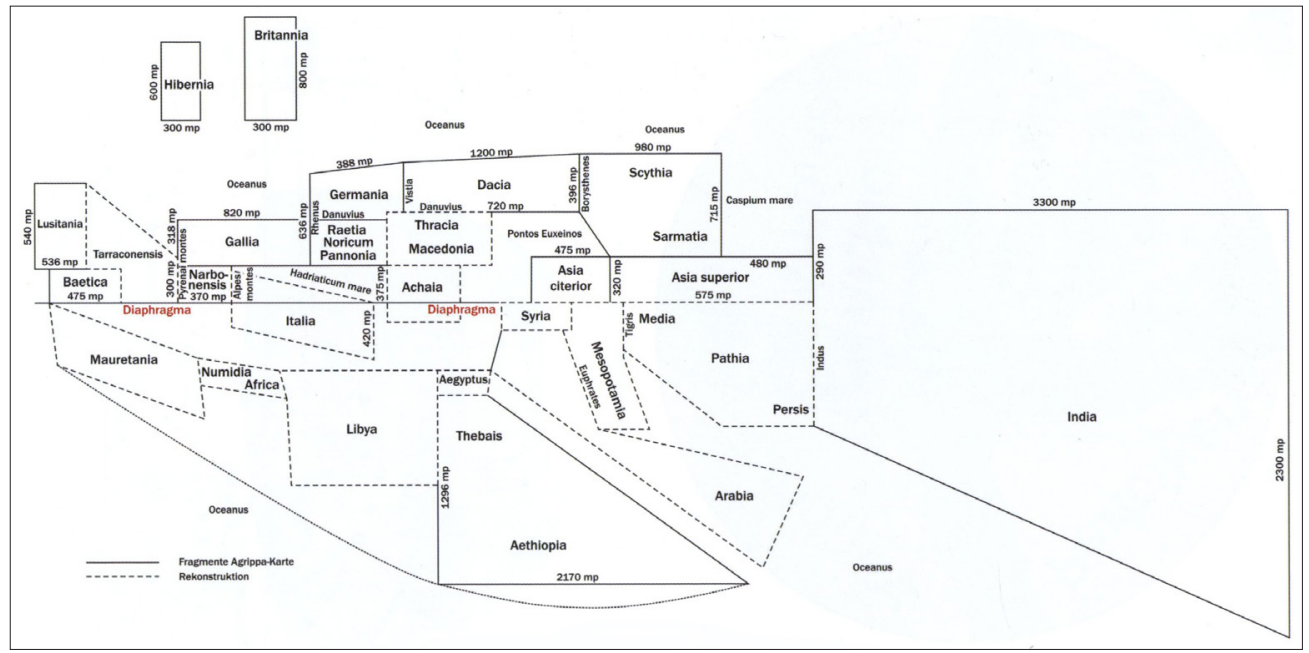

Fig. 6. Intento de reconstrucción del mapa de Agripa según los fragmentos transmitidos por Plinio. Hänger 2007, 140 fig. 1.

El mapa mundial del porticus Vipsania mostraba una oikumene dividida en 24 regiones, cuyas formas (rectángulos de distinto tamaño, con indicación del largo y el ancho) recordaban las figuras geométricas de Eratóstenes (Fig. 6). ${ }^{92}$ Las montañas, los ríos y los litorales estaban representados en forma de líneas, que a su vez formaban figuras geométricas. Cada una de estas figuras de diferentes medidas se alineaba a continuación de la otra, dando lugar necesariamente a divergencias en la orientación y a una deformación del paisaje representado. Existía una clara conciencia de la brecha existente entre las hipotéticas figuras geométricas y el espacio palpable, que se

89 Liv., 41.28.8-10: (...) Sardiniae insulae forma erat atque in ea simulacra pugnarum picta.

90 Plin., nat. 35.23 .

91 MoATti 1997, 66-67, hablando incluso de un "cours de géographie populaire"; más crítico en cambio se muestra CADIOU 2006, 135-152, sobre todo 139-140.

92 Como no ha llegado hasta nosotros, se han hecho intentos para reconstruir el mapa de Agripa a partir de las citas y las referencias de Plinio, que además alude a unos commentarii que habría dejado el propio Agripa, al respecto HäNGer 2007, 135-142; véase también Dilke 1985, 39-54; Gómez Fraile - AlbaladeJo Vivero 2012, 359-424, esp. 394-419. 
agrandaba a medida que avanzaba el conocimiento basado en la experiencia. ${ }^{93}$ Entre el enfoque científico reflejado en el mapa de Agripa y la orientación práctica del día a día había una distancia abismal. Con el primero estaban familiarizados los miembros de su grupo social; a la última, fundamentada sobre todo en la experiencia, se acudía cuando las circunstancias así lo requerían. En cualquier caso, el mapamundi del porticus Vipsania cumplió sin ninguna duda su función: completaba las Res Gestae que se alzaban a unos cientos de metros del mausoleo de Augusto y visualizaba el ámbito social y geográfico que Roma controlaba y administraba desde su principado. Y ese fue el mundo que Roma seguiría teniendo en la mente desde entonces.

\section{BibLiOgRAFÍA}

Abad Casal, L. - Keay, S. - Ramallo Asensio, S. (eds.) (2006): Early Roman Towns in Hispania Tarraconensis (= JRA. Suppl. 62), Portsmouth (R.I.).

Abascal Palazón, J. M.

(2006): "Los tres viajes de Augusto a Hispania y su relación con la promoción jurídica de las ciudades", Iberia 9, 63-78.

(2011): "La administración itinerante en la Hispania Citerior. El funcionario y su familia", [en] J. M. Iglesias Gil - A. Ruiz Gutiérrez (eds.), Viajes y cambios de residencia en el mundo romano, Santander, 289-317.

ALFöLDY, G.

(1978): "s.v. Tarraco", [en] RE Suppl. 15, 570-644 (revisado en castellano: Tàrraco [= Fòrum 8], Tarragona).

(1989): "Zu den Monumenten der römischen Provinzen auf dem Augustusforum", [en] H.-J. Drexhage - J. Sünskes (eds.), Migratio et Commutatio. Studien zur Alten Geschichte und deren Nachleben. Festschrift T. Pekáry, St. Katharinen, 226-235.

Amela Valverde, L. (2000): "Las ciudades fundadas por Pompeyo Magno en Occidente: Pompaelo, Lugdunum Convenarum y Gerunda", Polis 12, 7-41.

Andreu Pintado, J. (ed.) (2009): Los vascones de las fuentes antiguas. En torno a una etnia de la antigüedad peninsular (= Col.lecció Instrumenta 32), Barcelona.

Aquilué Abadías, X. (ed.) (2012): Empúries. Municipium Emporiae (= Ciudades Romanas de Hispania 6), Roma.

Aquilué Abadías, X. - Castanyer, P. - Santos, M. - Tremoleda, J. (2006): “The Greek City of Emporion and its Relationship to the Roman Republican City of Empúries", [en] Abad Casal - Keay - Ramallo Asensio (eds.), 2006, 18-31.

Ariño Gil, E. - Gurt i Esparraguera, J. M. - Palet Martínez, J. M. (2004): El pasado presente. Arqueología de los paisajes en la Hispania romana (= Acta Salmanticensia. Estudios geográficos y históricos 122), Salamanca.

Asensio Estebán, J. Á.

(1995): La ciudad en el mundo prerromano en Aragón (= Caesaraugusta 70), Zaragoza.

93 Cf. Podossinov 2000, 225-240; Engels 2007, 123-134, en concreto 125; Rathmann 2013, 11-49, en concreto 26 . 
(2003): "Urbanismo romano republicano en la región de la cuenca del Ebro (Hispania Citerior), 179-44 a.e", AEA 76, 159-178.

Aubet $\left(2001^{2}\right)$ : The Phoenicians and the West. Politics, Colonies and Trade, Cambridge. Aujac, G. (2001): Ératosthène de Cyrène, le pionnier de la géographie. Sa mesure de la circonférence terrestre (= Comité des Travaux Historiques et Scientifiques 39), Paris.

Austin, N. J. E. - Rankov, N. B. (1995): Exploratio. Military and political intelligence in the Roman world from the Second Punic War to the battle of Adrianople, London - New York.

BARrandon, N. (2011): De la pacification à l'integration des Hispaniques (133-27 a.C.). Les mutations des sociétés indigènes d'Hispanie centrale et septentrionale sous domination romaine (= Scripta Antiqua 35$)$, Bordeaux.

Beck, H. - Walter, U. (eds.) (2001): Die Frühen Römischen Historiker. Vol. 1: Von Fabius Pictor bis Cn. Gellius (= Texte zur Forschung 76), Darmstadt.

Bedon, E. (2003): "Les agglomérations indigènes de la péninsule ibérique chez Tite-Live", Gerión 21, 229-263.

BELTRÁN LLORIS, F.

(2006): "El valle medio del Ebro durante el período republicano: de limes a conventus", [en] Cruz Andreotti - Le Roux - Moret (eds.), 217-240.

(2007): "Locorum nuda nomina? La estructura de la descripción pliniana de Hispania", [en] Cruz Andreotti - Le Roux - Moret (eds.), 115-160.

(2012): "Plinio versus Ptolomeo. Geografía y etnicidad en la Hispania del Principado", [en] Santos Yanguas - Cruz Andreotti (eds.), 477-498.

(1987): "El valle medio del Ebro y su monumentalización en época republicana augustea (Antecedentes, Lepida-Celsa y Caesaraugusta)", [en] Trillmich - Zanker (eds.), 179-204.

Beltrán Lloris, F. (ed.), (2007): Las capitales provinciales de Hispania. Vol. 4: Zaragoza. Colonia Caesar Augusta (= Ciudades Romanas de Hispania 4), Roma.

Beltrán Lloris, F. - FAtás CabezA, G. (1998): César Augusta, ciudad romana (= Historia de Zaragoza 2), Zaragoza.

Beltrán Lloris, F. - Martín-Bueno, M. - Pina Polo, F. (2000): Roma en la Cuenca Media del Ebro. La romanización en Aragón (= Colección Mariano de Pano y Ruata 19), Zaragoza.

Beltrán Lloris, F. - Mostalac Carrillo, A. (2008): “La Colonia Lepida/Celsa y Salduie: sus testimonios arqueológicos durante el segundo triunvirato y comienzos del imperio", [en] M. P. García-Bellido - A. Mostalac Carrillo - A. Jiménez Díez (eds.), Del imperium de Pompeyo a la auctoritas de Augusto. Homenaje a Michael Grant (= Anejos de Archivo Español de Arqueología 47), Madrid, 107-127.

Beltrán Lloris, F. - PinA Polo, F. (1994): "Roma y los Pirineos: la formación de una frontera", Chiron 24, 103-133.

Berger, E. H. (1964) [ND 1880]: Die geographischen Fragmente des Eratosthenes, Amsterdam.

Bleicken, J. (1999³): Augustus. Eine Biographie, Berlin.

Brodersen, K. (1995): Terra Cognita. Studien zur römischen Raumerfassung (= Spudasmata 59), Hildesheim. 
Burch, J. - Nolla Brufau, J. M. - Sagrera, J. (2010): “L'oppidum ibérique de Sant Julià de Ramis", [en] H. Tréziny (ed.), Grecs et indigènes de la Catalogne à la Mer Noire (= Bibliothèque d'Archéologie Méditerranéenne et Africaine 3), Paris-Aix-en-Provence, 119-127.

Caballos Rufino, A. (1990): Los senadores hispanorromanos y la romanización de Hispania (Siglos I al III p.C.). Vol. 1: Prosopografía, Écija.

Cabrera Bonet, P. - SÁnchez Fernández, C. (eds.) (2000): Los griegos en España. Tras las huellas de Heracles, Madrid.

CAdiou, F. (2006): "Renseignement, espionnage et circulation des armées romaines: vers une géographie militaire de la Péninsule Ibérique à l'époque de la conquête", [en] Cruz Andreotti - Le Roux - Moret (eds.), 135-152.

Camacho Rojo, J. M. - Fuentes González, P. P. (2012): “s.v. Pythéas de Marseille”, [en] R. Goulet (ed.), Dictionnaire des Philosophes Antiques. Vol. 5.2, Paris, 1774-1780.

Chasseigne, L. - Fincker, M. et ALII (2006): "Labitolosa and other Roman Towns on the South Side of the Pyrenees", [en] Abad Casal - Keay - Ramallo Asensio (eds.), 146-158.

Clariana i Roig, J. F. (2001): "D'Ilturo a Iluro: d'ibers a romans. Algunes consideracions", [en] XVIII Sessió d'Estudis Mataronins 2001, Mataró, 19-52.

Comas i SolÀ, M. - Surroca I Coret, J. (2003): Baetulo, ciutat romana, Badalona.

Cruz Andreotti, G.

(2006): "La integración histórico-geográfica de la Península Ibérica”, [en] Cruz Andreotti - Le Roux - Moret (eds.), 77-96.

(2007): “Acerca de Estrabón y la Turdetania-Bética”, [en] Cruz Andreotti - Le Roux Moret (eds.), 251-270.

Cruz Andreotti, G. - Le Roux, P. - Moret, P. (eds.)

(2006): La invención de una geografía de la Península Ibérica. Vol. 1: La época republicana / L'invention d'une géographie de la Péninsule Ibérique. I. L'époque républicaine. Coloquio internacional. Madrid 2005, Málaga - Madrid.

(2007): La invención de una geografía de la Península Ibérica. Vol. 2: La época imperial / L'invention d'une géographie de la Péninsule Ibérique. II. L'époque impériale. Coloquio internacional. Madrid 2006, Málaga-Madrid.

Curchin, L. A. (1991): Roman Spain. Conquest and Assimilation, London - New York.

DiLke, O. A. W.

(1985): Greek and Roman Maps (= Aspects of Greek and Roman Life), London.

(1987): "Maps in the Service of the State: Roman Cartography to the End of the Augustan Era”, [en] J.B. Harley - D. Woodward (eds.), The History of Cartography. Vol. I: Cartography in Prehestoric, Ancient and Medieval Europe and the Mediterranean, Chicago - London, 201-211.

Dion, R. (1997): Aspects politiques de la géographie antique, Paris.

Domínguez Monedero, A. J. (2005): “Organización urbana e incidencia romana”, [en] A. Chaín Galán - J. I. de la Torre Echávarri (eds.), Celtíberos. Tras la estela de Numancia, Soria, 119-127 y 285-292.

Dopico Caínzos, M. D. - Santos Yanguas, J. (2012): “La adecuación de las entidades indígenas a la nueva administración romana: el ejemplo de los conventus del noroeste peninsular", [en] Santos Yanguas - Cruz Andreotti (eds.), 581-600. 
Dupré Raventós, X. (ed.) (2004): Las capitales provinciales de Hispania. Vol. 3: Tarragona. Colonia Iulia Urbs Triumphalis Tarraco (= Ciudades Romanas de Hispania 3), Roma.

EngeLs, J. (2007): "Die Raumauffassung des augusteischen Oikumenereiches in den Geographika Strabons", [en] Rathmann (ed.), 123-134.

Escribano PAÑo, M. V. (1998): Zaragoza en la Antigüedad tardia (285-714) (= Historia de Zaragoza 3), Zaragoza.

EsPinosa EsPinOsa D. (2014): Plinio y los “oppida de antiguo Lacio”. El proceso de difusión del Latium en Hispania Citerior (= BAR. International Series 2686), Oxford.

FAtÁs CABezA, G. (1998): “El Ebro medio, trifinio paleohispánico”, [en] J. F. Rodríguez Neila - F. J. Navarro Santana (eds.), Los pueblos prerromanos del norte de Hispania. Una transición cultural como debate histórico, Pamplona, 29-50.

Fatás Cabeza, G. - Beltrán Lloris, F. (1997): Salduie, ciudad ibérica (= Historia de Zaragoza 1), Zaragoza.

Ferreruela Gonzalvo, A. - Mínguez Morales, J. A.

(2002): "La Cabañeta (El Burgo de Ebro, Zaragoza)", [en] Jiménez Salvador - Ribera i Lacomba, 205-214.

(2003): "Dos modelos de implantación urbana romanorrepublicana en el valle medio del Ebro: las ciudades de La Cabañeta y La Corona", AEA 76, 247-262.

Fuentes Domínguez, Á. (1997): "Valeria. Historia del yacimiento y resultado de las últimas investigaciones", [en] M. Almagro-Gorbea (ed.), Ciudades romanas en la provincia de Cuenca. Homenaje a F. Suay Martínez, Cuenca, 103-132.

Gallazzi, C. - Kramer, B. (1998): “Artemidor im Zeichensaal. Eine Papyrusrolle mit Text, Landkarte aus späthellenistischer Zeit”, APF 44, 189-208.

GARCía Fernández, E. (2009): "Graccurris y los oppida de antiguo Lacio", [en] Andreu Pintado (ed.), 215-230.

GARCÍA-Bellido, M. P. (2003): “La historia de la colonia Lepida-Celsa según sus documentos numismáticos: su ceca imperial”, AEA 76, 273-290.

GeHrKe, H.-J. (1998): "Die Geburt der Erdkunde aus dem Geiste der Geometrie. Überlegungen zur Entstehung und zur Frühgeschichte der wissenschaftlichen Geographie bei den Griechen", [en] W. Kullmann - J. Althoff - M. Asper (eds.), Gattungen wissenschaftlicher Literatur in der Antike (= ScriptOralia 95), Tübingen, 163-192.

GEus, K. (2002): Eratosthenes von Kyrene. Studien zur hellenistischen Kultur- und Wissenschaftsgeschichte (= Münchener Beiträge zur Papyrusforschung und antiken Rechtsgeschichte 92), München.

GIL, I. - LORIENTE, A. ET ALII (2001): "De la Iltirta prerromana a la Ilerda tardorromana. Nuevos datos tras dos décadas de investigación continuada en Lleida", AEA 74, 161-174.

Gómez EsPelosín, F. J. (2005): "Exploraciones y descubrimientos en el occidente en la obra de Polibio", [en] J. Santos Yanguas - E. Torregaray (eds.), Polibio y la Península Ibérica (= Anejos de Veleia. Acta 4 / Revisiones de Historia Antigua 4), Vitoria-Gasteiz, 113139.

Gómez Fraile, J. M. - Albaladejo Vivero, M. (2012): “Geografía literaria y límites provinciales: la Península Ibérica entre Eratóstenes y Agripa”, [en] Santos Yanguas - Cruz Andreotti (eds.), 359-424. 
Gozalbes Cravioto, E. (2012): "La ciudad hispano-romana de Valeria. Estado actual de los conocimientos", [en] G. Carrasco Serrano (ed.), La ciudad romana en Castilla-La Mancha. Coloquio internacional. Castilla-La Mancha 2010 (= Estudios 134), Cuenca, 161-200.

Gozalbes Cravioto, E. (ed.), (2009): La ciudad romana de Valeria (Cuenca) (= Colección Humanidades 111), Cuenca.

Guitart, J. - PADrós, P. (1990): "Baetulo, cronología y significación de sus monumentos”, [en] Trillmich - Zanker (eds.), 165-177.

Guitart i Duran, J. (2006): "Iluro, Baetulo, Iesso, and the Establishment of the Roman Town Model in Catalunya", [en] Abad Casal - Keay - Ramallo Asensio (eds.), 51-61.

HÄNGER, C. (2007): “Die Karte des Agrippa”, [en] Rathmann (ed.), 135-142.

Hagenow, G. (1932): Untersuchungen zu Artemidors Geographie des Westens, Quakenbrück.

Halfmann, H. (1986): Itinera principum. Geschichte und Typologie der Kaiserreisen im Römischen Reich (= HABES 2), Stuttgart.

Harley, J. B. - Woodward, D. (eds.) (1987): The History of Cartography. Vol. I: Cartography in Prehestoric, Ancient and Medieval Europe and the Mediterranean, Chicago - London.

HaSElberger, L. (2007): Urbem adornare. Die Stadt Rom und ihre Gestaltumwandlung unter Augustus (= JRA. Suppl. 64), Portsmouth (R.I.).

Hennig, R. (1944²): Terrae Incognitae. Eine Zusammenstellung und kritische Bewertung der wichtigsten vorcolumbischen Entdeckungsreisen an Hand der darüber vorliegenden Originalberichte. Bd. 1: Altertum bis Ptolemäus, Leiden.

Hernández Vera, J. A. (2002): “La fundación de Graccurris”, [en] Jiménez Salvador - Ribera i Lacomba, 173-182.

HöLSCHER, T. (2000): “Augustus und die Macht der Archäologie”, [en] F. Millar (ed.), La révolution romaine après $R$. Syme. Bilans et perspectives (= Fondation Hardt pour l'Étude de l'Antiquité Classique Entretiens 46), Genf, 237-281.

JANNI, P. (1984): La mappa e il periplo. Cartografia antica e spazio odologico, Roma.

JimÉnez SAlVADOR, J. L. - RiBERA I LACOMBA, A. (2002): Valencia y las primeras ciudades romanas de Hispania, Valencia.

Kallet-MarX, R. M. (1995): Hegemony to Empire. The Development of the Roman Imperium in the East from 148 to 62 B.C. (= Hellenistic Culture and Society 15), Berkeley.

Kienast, D. (20094): Augustus. Prinzeps und Monarch, Darmstadt.

KNAPP, R. C. (1997): Aspects of the Roman Experience in Iberia, 206-100 B.C., VitoriaGasteiz.

KocH, M. (1993): Animus... meus ... praesagit, nostrum Hispaniam esse, [en] W. Trillmich -T. Hauschild (eds.), Hispania Antiqua. Denkmäler der Römerzeit, Mainz, 1-40.

Kramer, B. (2006): “La Península Ibérica en la Geografía de Artemidoro de Éfeso", [en] Cruz Andreotti - Le Roux - Moret (eds.), 97-114.

KüHnen, A. (2008): Die imitatio Alexandri in der römischen Politik (1. Jh. v. Chr.-3. Jh. n. Chr.), Münster. 
Le RouX, P.

(1995): Romains d'Espagne. Cités et politique dans les provinces. II siècle av. J.-C.-III siècle ap. J.-C., Paris.

(1999): "La ville romaine en Hispanie", [en] L. Tavares Dias - J. M. Araújo (eds.), Emergência e desenvolvimento das cidades romanas no Norte da península Ibérica, Porto, 233250.

Lintott, A. (1993): Imperium Romanum. Politics and Administration, London - New York.

López de la Orden, M. D. (ed.), (2011): Cádiz y Huelva. Puertos fenicios del Atlántico, Sevilla.

Mackie, N. (1983): Local Administration in Roman Spain A.D. 14-212 (= BAR. International Series 172), Oxford.

Magallón Botaya, M. Á. - Sillières, P. (eds.) (2013): Labitolosa (La Puebla de Castro, province de Huesca, Espagne): una citè romaine de l'Hispanie citérieure (= Mémoires Ausonius 33), Bordeaux.

Mar Medina, R. - Ruiz de Arbulo Bayona, J. (1993): Ampurias romana. Historia, arquitectura y arqueología, Sabadell.

Marco Simón, F. (2003): Los pueblos antiguos de la Cuenca del Ebro, Zaragoza.

Marcotte, D. (2011): “Le Papyrus d'Artemidore: le livre, le texte, le débat”, RHT 5, 333371.

Martín Menéndez, A. - García Roselló, J. (2002): “La romanización en el territorio de los Layetanos y la fundación de la ciudad romana de Iluro (Hispania Tarraconensis)", [en] Jiménez Salvador - Ribera i Lacomba, 195-204.

Mette, H. J. (1952): Pytheas von Massalia (= Kleine Texte für Vorlesungen und Übungen 173), Berlin.

Mostтi, C. (1997): La raison de Rome. Naissance de l'esprit critique à la fin de la République (II - I ${ }^{\text {er }}$ siècle avant Jésus-Christ), Paris.

Moret, P. (2012): “Artemidoro y la ordenación territorial de Hispania en época republicana", [en] Santos Yanguas - Cruz Andreotti (eds.), 425-456.

Murphy, T. (2004): Pliny the Elder's Natural History. The Empire in the Encyclopedia, Oxford.

NAAs, V. (2002): Le projet encyclopédique de Pline l'Ancien (= Collection de l'École Française de Rome 303), Roma.

Nicolet, C.

(1988): L'inventaire du monde. Géographie et politique aux origines de l'Empire romain, Paris.

(1991): "L'origine des regiones Italiae augustéennes", $C C G$ 2, 73-97.

Nolla Brufau, J. M. - Palahí, L. - Vivo Codina, D. (2010): De l'oppidum a la civitas. La romanització inicial de la Indigècia, Girona.

Olcoz Yanguas, S. - Medrano Marqués, M. M. (2006): “Tito Livio: Castra Aelia y el límite meridional del ager Vasconum, antes y después de Sertorio", [en] Navarra: memoria e imagen. Actas del Congreso de Historia de Navarra. Pamplona 2006. Vol. 1: La herencia de la Prehistoria y de la Antigüedad, Pamplona, 55-75.

OzCÁRIz GIL, P. (2012): "Divisiones administrativas conventuales y realidades etno-territoriales”, [en] Santos Yanguas - Cruz Andreotti (eds.), 557-579. 
Panzram, S. (2002): Stadtbild und Elite. Tarraco, Corduba und Augusta Emerita zwischen Republik und Spätantike (= Historia Einzelschriften 161), Stuttgart.

PAyÀ Mercé, X. (2004): "Primers indicis fundacionals de la ciutat d'Ilerda en època republicana tardana", Revista d'Arqueologia de Ponent 14, 323-324.

PayÀ Mercé, X. - GiL, I. et ALII (1996): "Evolució espacial i cronològica de l'antiga ciutat d'Ilerda", Revista d'Arqueologia de Ponent 6, 119-149.

PÉDECH, P. (1964): La méthode historique de Polybe, Paris.

Pera IsERn, J. (1997): “Iesso i Sigarra en el marc de la romanització de la Citerior”, Revista d'Arqueologia de Ponent 7, 229-236.

Pina Polo, F. (1993): “¿Existió una política romana de urbanización en el nordeste de la Península Ibérica?", Habis 24, 77-94.

(1997): “Las comisiones senatoriales para la reorganización de Hispania (App. Iber. 99100)", DHA 23, 83-104.

(2003): “¿Por qué fue reclutada la turma Salluitana en Salduie?”, Gerión 21, 197-204.

(2003): "Introducción: El valle medio del Ebro entre el mestizaje cultural y la frontera militar", AEA 76, 155-158.

(2004): "Deportaciones como castigo e instrumento de colonización durante la República Romana: El caso de Hispania", [en] F. Marco Simón - F. Pina Polo - J. Remesal Rodríguez (eds.), Vivir en tierra extraña. Emigración e integración cultural en el mundo antiguo, Barcelona, 211-246.

(2007): "Kontinuität und Innovation im Städtenetzwerk der nordöstlichen iberischen Halbinsel zur Zeit der Republik", [en] S. Panzram (ed.), Städte im Wandel. Bauliche Inszenierung und literarische Stilisierung lokaler Eliten auf der Iberischen Halbinsel. Internationales Kolloquium. Hamburg 2005 (= Geschichte und Kultur der Iberischen Welt 5), Münster, 25-57.

(2009): "Sertorio, Pompeyo y el supuesto alineamiento de los Vascones con Roma", [en] Andreu Pintado (ed.), 195-214.

(2011): "Etnia, ciudad y provincia en la Hispania republicana", [en] A. Caballos Rufino

- S. Lefebvre (eds.), Roma generadora de identidades. La experiencia hispana (= Collection de la Casa de Velázquez 123), Madrid, 39-53.

Pina Polo, F. - Pérez Casas, J. Á. (1998): “El oppidum Castra Aelia y las campañas de Sertorius en los años 77-76 a.C.", JRA 11, 245-264.

Podossinov, A. V. (2000): "Die geographische Karte im Dienste des antiken Staates?", [en] M. Dreher (ed.), Bürgersinn und staatliche Macht in Antike und Gegenwart. Festschrift für W. Schuller zum 65. Geburtstag, Konstanz, 225-240.

Prontera, F. (2011): "La penisola iberica nella cartografia ellenistica", [en] F. Prontera, Geografia e storia nella Grecia antica (= Biblioteca di Geographia Antiqua 4), Firenze, 183-196.

RATHMANN, M.

(2011): "Der Artemidorpapyrus (P.Artemid.) im Spiegel der Forschung”, Klio 93, 350368.

(2013): "Kartographie in der Antike. Überlieferte Fakten, bekannte Fragen, neue Perspektiven", [en] D. Boschung - T. Greub - J. Hammerstaedt (eds.), Geographische Kenntnisse und ihre konkreten Ausformungen (= Morphomata 5), München, 11-49.

RathMANN, M. (ed.), (2007): Wahrnehmung und Erfassung geographischer Räume in der Antike, Mainz. 
Rehak, P. (2006): Imperium and Cosmos. Augustus and the Northern Campus Martius. Ed. by J.G. Younger, Madison (Wi.).

RiBERA I LACOMBA, A.

(2002): "El urbanismo de la primera Valencia", [en] Jiménez Salvador - Ribera i Lacomba (eds.), 299-313.

(2006): "The Roman Foundation of Valencia and the Town in the $2^{\text {nd }}-1^{\text {st }}$ c. B.C", [en]

Abad Casal - Keay - Ramallo Asensio (eds.), 75-89.

RICHARDSON, J. S.

(1996): The Romans in Spain, Oxford-Cambridge (Mass.).

(2004) [ND 1986]: Hispaniae. Spain and the Development of Roman Imperialism, 218-82 $B C$, Cambridge.

Roller, D. W. (2010): Eratosthenes 'Geography, Princeton-Oxford.

Romm, J. S. (1992): The Edges of the Earth in Ancient Thought. Geography. Exploration, and Fiction, Princeton.

SAlinas de Frías, M. (1995): El gobierno de las provincias Hispanas durante la República Romana (218-27 a.C.) (=Acta Salmanticensia. Estudios Históricos \& Geográficos 96), Salamanca.

Santos Yanguas, J. - Cruz Andreotti, G. (eds.) (2012): Romanización, fronteras y etnias en la Roma antigua: El caso hispano (=Anejos de Veleia. Acta 12 / Revisiones de Historia Antigua 7), Vitoria - Gasteiz.

SCHLEussner, B. (1978): Die Legaten der römischen Republik. Decem legati und ständige Hilfsgesandte (= Vestigia 26), München.

Stiehle, R. (1856): "Der Geograph Artemidoros von Ephesos”, Philologus 11, 193-244.

Trillmich, W. - Zanker, P. (eds.) (1990): Stadtbild und Ideologie. Die Monumentalisierung hispanischer Städte zwischen Republik und Kaiserzeit. Internationales Kolloquium. Madrid 1987 (= Bayerische Akademie der Wissenschaften. Philosophisch-historische Klasse. Abhandlungen, Neue Folge 103), München.

Trotta, F. (1999): “Estrabón, el libro III y la tradición geográfica”, [en] G. Cruz Andreotti (ed.), Estrabón e Iberia: nuevas perspectivas de estudio, Málaga, 81-99.

VAN DER VLIET, E.C.L. (1984): “L'Ethnographie de Strabon: Ideologie ou tradition?”, [en] F. Prontera (ed.), Strabone. Contributi allo studio della personalità e dell'opera, Perugia, 27-86.

VitTinghoff, F. (1952): Römische Kolonisation und Bürgerrechtspolitik unter Caesar und Augustus (= Akademie der Wissenschaften und der Literatur Mainz. Geistes- und sozialwissenschaftliche Klasse 14, 1951), Wiesbaden.

Walbank, F.W. (1979): A Historical Commentary on Polybios. Vol. 3: Commentary on Books 19-40, Oxford.

Wallace-Hadrill, A. (2005): "Mutatas Formas: The Augustan Transformation of Roman Knowledge", [en] K. Galinsky (ed.), The Cambridge Companion of the Age of Augustus, Cambridge, 55-84. 